\title{
Analytical Expressions of the Efficiency of Standard and High Contact Ratio Involute Spur Gears
}

\author{
Miguel Pleguezuelos, José I. Pedrero, and Miryam B. Sánchez \\ Departamento de Mecánica, UNED, ETS Ingenieros Industriales, Juan del Rosal 12, 28040 Madrid, Spain \\ Correspondence should be addressed to José I. Pedrero; jpedrero@ind.uned.es
}

Received 12 December 2012; Accepted 15 March 2013

Academic Editor: G. Rega

Copyright (C) 2013 Miguel Pleguezuelos et al. This is an open access article distributed under the Creative Commons Attribution License, which permits unrestricted use, distribution, and reproduction in any medium, provided the original work is properly cited.

\begin{abstract}
Simple, traditional methods for computation of the efficiency of spur gears are based on the hypotheses of constant friction coefficient and uniform load sharing along the path of contact. However, none of them is accurate. The friction coefficient is variable along the path of contact, though average values can be often considered for preliminary calculations. Nevertheless, the nonuniform load sharing produced by the changing rigidity of the pair of teeth has significant influence on the friction losses, due to the different relative sliding at any contact point. In previous works, the authors obtained a nonuniform model of load distribution based on the minimum elastic potential criterion, which was applied to compute the efficiency of standard gears. In this work, this model of load sharing is applied to study the efficiency of both standard and high contact ratio involute spur gears (with contact ratio between 1 and 2 and greater than 2, resp.). Approximate expressions for the friction power losses and for the efficiency are presented assuming the friction coefficient to be constant along the path of contact. A study of the influence of some transmission parameters (as the gear ratio, pressure angle, etc.) on the efficiency is also presented.
\end{abstract}

\section{Introduction}

The efficiency of the gear transmissions may have significant influence not only on the direct operating costs and the operating lives but also on the environmental impact associated to power loss. The efficiency of involute gears is usually high, but uncontrolled friction phenomena may result in surface defects arising after operating periods shorter than the expected ones. These defects will produce higher losses, noise, vibrations, and heat generation during the operation, which may result in the complete failure of the transmission even.

Classic, simple models of efficiency of spur gears available in technical literature [1-5] are based on the hypotheses of constant friction coefficient and uniform load sharing along the path of contact. Neither of them is accurate, but the efficiency of spur gears is high, and very accurate calculations were not required in the past. However, the rapidly rising trend of transmitted power to size ratio may make more accurate models suitable. In this sense, variations of the friction coefficient along the path of contact can be neglected if average values are considered $[2,3,5]$. Nevertheless, errors induced for considering uniform load sharing between couples of teeth in simultaneous contact may be high, especially if errors are expressed in terms of power losses.

Empirical models for load distribution and constant friction coefficient have been used in some studies, as ones of Michlin and Myunster [6] and Höhn et al. [7]. A preliminary authors' study using a nonuniform load distribution model can be found in [8]. Other models using nonuniform friction coefficient models have been reported by Anderson et al. [911], Vaishya and Houser [12], Lehtovaara [13], and Diab et al. [14]. More complex models using the elastohydrodynamic lubrication theory to formulate the variation of the friction coefficient avoiding the necessity of experimental results have been developed by Martin [15] and Wu and Cheng [16]. A similar model combined with load distribution models, including experimental validation, was presented by $\mathrm{Xu}$ [17]. Many other studies to compute the power loss based on experimental data can be found in technical literature [1822]. From a theoretical point of view, Velex and Ville [23] formulate the problem using generalized displacements and 


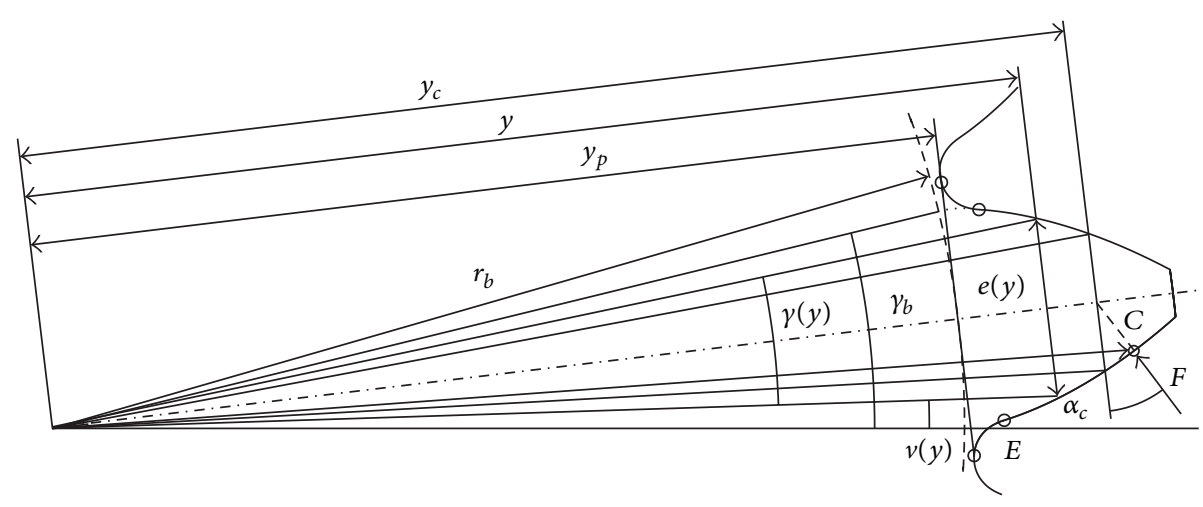

FIGURE 1: Geometrical parameters of involute tooth.

incorporate the influence of profile modifications to propose analytical formulae of tooth friction power losses in spur and helical gears.

The authors developed a model of load distribution along the line of contact based on the minimum elastic potential (MEP) criterion [24-26] and applied it to the determination of the efficiency of spur gears, considering average, constant values of the friction coefficient [27-30]. Obtained results provide values of the efficiency slightly greater than those obtained from the traditional models [1-5]. A preliminary model of efficiency based on the MEP load distribution and a very simple model of nonconstant friction coefficient were also developed and can be found in [31].

In this work, a similar model for the efficiency of spur gears has been developed, considering both standard spur gears with contact ratio between 1 and 2 and high contact ratio spur gears, with contact ratio up to 2.7. The model is based on the application of the MEP nonuniform model of load distribution along the line of contact and assuming the friction coefficient to be constant along the path of contact. Analytical, approximate expressions for the power losses due to friction, for the transmitted power and for the efficiency, are presented. The efficiency has been expressed by a simple, analytic equation as a function of only three parameters: the number of teeth on pinion and wheel and the transverse contact ratio. From this equation, a complete study of the influence of some design parameters (as the number of teeth, the gear ratio, the pressure angle, the addendum modification coefficient, etc.) on the efficiency is also presented.

\section{Load Distribution Model}

References [24, 25] present in detail the model of load sharing of minimum elastic potential energy. It is based on the assumption that the load sharing among couples of teeth in simultaneous contact provides a minimum elastic potential energy. It has been obtained by computing the total elastic potential energy, considering all the pairs of teeth in simultaneous contact, with an unknown fraction of the load acting on each one, and minimizing its value by means of variational techniques. In this section, the model will be briefly described.
The elastic potential energy of a spur tooth $U$ can be expressed as the sum of the bending component $U_{x}$, the compressive component $U_{n}$, and the shear component $U_{s}$ :

$$
U=U_{x}+U_{n}+U_{s}
$$

All the components can be computed from the equations of the theory of elasticity and some geometrical parameters of the tooth which have been represented in Figure 1. The application of those equations to the geometry of the involute teeth results in:

$$
\begin{aligned}
& U_{x}=6 \frac{F^{2} \cos ^{2} \alpha_{C}}{E b} \int_{y_{p}}^{y_{C}} \frac{\left(y_{C}-y\right)^{2}}{e^{3}(y)} d y, \\
& U_{n}=\frac{1}{2} \frac{F^{2} \sin ^{2} \alpha_{C}}{E b} \int_{y_{p}}^{y_{C}} \frac{d y}{e(y)}, \\
& U_{s}=C \frac{1}{2} \frac{F^{2} \cos ^{2} \alpha_{C}}{G b} \int_{y_{p}}^{y_{C}} \frac{d y}{e(y)},
\end{aligned}
$$

where $F$ is the normal load between both teeth, $\alpha_{C}$ the load angle, $b$ the face width, $E$ the modulus of elasticity of the material, $G$ the transverse modulus of elasticity, and $e(y)$ the tooth chordal thickness at the section described by $y$, being $y$ the coordinate along the tooth centerline from the gear rotation center. $y_{p}$ and $y_{C}$ are the values of coordinate $y$ corresponding to the embedded section (defined by the points of both sides of the profile at the root circle) and to the load section (defined by the intersection of the line of action of the load-i.e., the normal to the profile at the contact point-and the tooth centerline), respectively. Finally, $C$ is the shear potential correction factor, which accounts the nonuniform distribution of the shear stresses on the section, according to the Colignon's theorem. For rectangular section, this factor takes the value $C=1.5$.

To describe the contact point, the profile parameter $\xi$ is defined as [24, 25]

$$
\xi=\theta \frac{Z}{2 \pi}=\frac{Z}{2 \pi} \sqrt{\frac{r_{\xi}^{2}}{r_{b}^{2}}-1,}
$$


where $\theta$ is the involute rotation angle, $Z$ the number of teeth, $r_{\xi}$ the radius of the contact point, and $r_{b}$ the base radius. Note that the difference of $\xi$ parameters corresponding to contact at the outer point of contact and at the inner point of contact is equal to the transverse contact ratio $\varepsilon_{\alpha}$. Similarly, the difference of $\xi$ parameters corresponding to two contiguous teeth in simultaneous contact is equal to 1 .

According to this, the elastic potential energy of a tooth can be expressed as a function of the profile parameter of its load point (or contact point), $U=U(\xi)$. Of course, this is valid both for the pinion tooth and for the wheel tooth, so that

$$
\begin{aligned}
& U_{1}=U_{1}(\xi), \\
& U_{2}=U_{2}\left(\xi_{2}\right),
\end{aligned}
$$

where subscripts 1 and 2 denote the pinion and the wheel, respectively (for simplicity, the pinion profile parameter will be denoted by $\xi$, without subscript). The sum of the curvature radii of both transverse profiles at the respective contact points is constant along the line of action and equal to the distance between the tangency points of the operating pressure line and both base circles of pinion and wheel, which provides a relation between pinion and wheel profile parameters:

$$
\xi+\xi_{2}=\lambda_{\xi}=\frac{Z_{1}+Z_{2}}{2 \pi} \tan \alpha_{t}^{\prime},
$$

where $\alpha_{t}^{\prime}$ is the operating transverse pressure angle (the pressure angle at the pitch cylinder) and $\lambda_{\xi}$ the distance between both tangency points divided by the base radius and the angular pitch of the pinion. The potential energy of a pair of teeth in contact $U_{p}$ will be the sum of those of the pinion and the wheel, which, according to (5), may be expressed as a function of the pinion profile parameter $\xi$ :

$$
U_{p}=U_{1}+U_{2}=U_{p}(\xi) .
$$

Finally, two more parameters are defined [24, 25]: the unitary potential $u$, which is the elastic potential for unit load and face width, and the inverse unitary potential $v$, which is the inverse of $u$ :

$$
\begin{gathered}
u(\xi)=\frac{b}{F^{2}} U_{p}(\xi), \\
v(\xi)=\frac{1}{u(\xi)},
\end{gathered}
$$

being $F$ the load carried by the pair of teeth. Both the unitary potential and the inverse unitary potential of a determined pair of teeth can be computed from the above equations by numerical techniques of integration. The result for standard teeth is always a function of $\xi$ similar to that in Figure 2.

For spur gears, the elastic potential energy is computed considering all the pairs of teeth in simultaneous contact, with an unknown fraction of the load acting on each one, and minimizing its value by means of variational techniques (Lagrange's method). The load at each pair results in [24, 25]

$$
F_{i}\left(\xi_{i}\right)=\frac{v_{i}\left(\xi_{i}\right)}{\sum_{j=0}^{z_{1}-1} v_{j}\left(\xi_{j}\right)} F,
$$

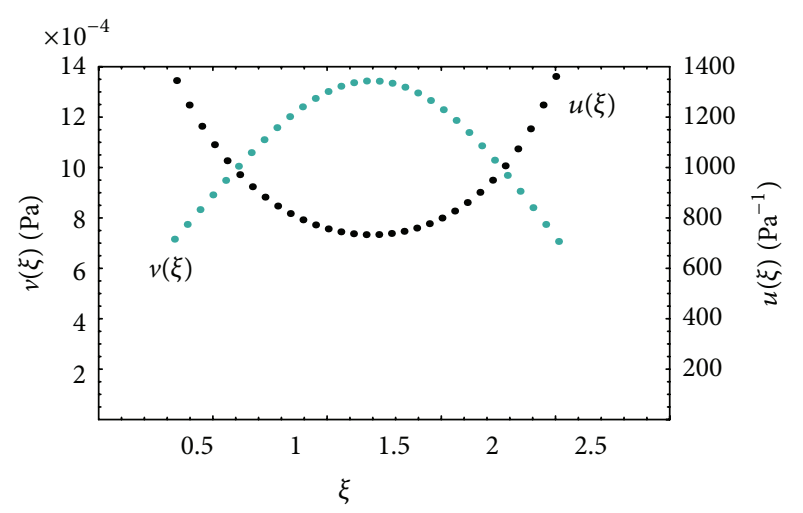

Figure 2: Example of unitary potential $u$ and inverse unitary potential $v$ for spur gears (obtained by numerical integration of the equations of the elasticity).

where $F_{i}\left(\xi_{i}\right)$ and $v_{i}\left(\xi_{i}\right)$ are the load and the inverse unitary potential of tooth $i$ when contact occurs at the point corresponding to $\xi_{i}, F$ is the total transmitted load, and it is assumed $v_{i}\left(\xi_{i}\right)=0$ outside the interval of contact $\xi_{\text {inn }} \leq \xi \leq$ $\xi_{\text {inn }}+\varepsilon_{\alpha}$, where $\xi_{\text {inn }}$ is the profile parameter corresponding to the inner contact point of the pinion. According to this, the load sharing ratio $R(\xi)$ (or the fraction of the load supported by the considered pair of teeth) is given by

$$
R_{i}\left(\xi_{i}\right)=\frac{F_{i}\left(\xi_{i}\right)}{F}=\frac{v_{i}\left(\xi_{i}\right)}{\sum_{j=0}^{z_{1}-1} v_{j}\left(\xi_{j}\right)}=\frac{v\left(\xi_{i}\right)}{\sum_{j=0}^{z_{1}-1} v\left(\xi_{i}+(j-i)\right)},
$$

while the load per unit of length $f(\xi)$, for spur gears, can be expressed as

$$
f_{i}\left(\xi_{i}\right)=\frac{F}{b} R_{i}\left(\xi_{i}\right)
$$

The load sharing model presented in (9) can be only calculated by using computational methods and numerical integration techniques to compute the elastic potential energy, whose domains are defined by the geometry of the involute and the trochoid of pinion and wheel. Equations for active and root profiles can be found in [25]. To perform these calculations, a powerful automated numerical and symbolic computation system is required, and all the above equations have been implemented in MATHEMATICA [32]. This allows computing the load sharing for any spur gear pair numerically. However, to develop an analytical model of efficiency, an analytic function for the inverse unitary potential is required [27].

If we define a new parameter $\zeta$ of the profile points as $\zeta=$ $\xi-\xi_{\text {inn }}$, the interval between contact at the inner point of contact and the next tooth contacting at the inner point of contact is given by $0 \leq \zeta \leq 1$, and the complete meshing interval of a tooth is given by $0 \leq \zeta \leq \varepsilon_{\alpha}$. 


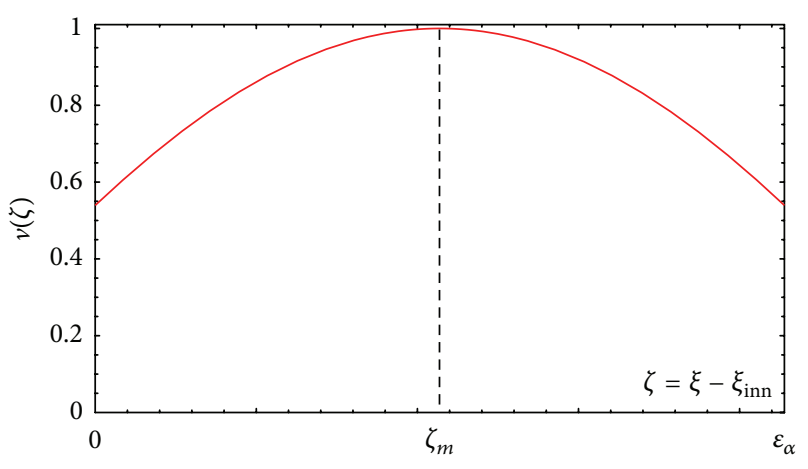

Figure 3: Typical shape of the graph of inverse unitary potential $v(\zeta)$.

The inverse unitary potential $v$ can be expressed as a function of this new parameter $\zeta$. This expression can be accurately approximated by equation [25]:

$$
\begin{aligned}
v(\zeta) & =\cos \left[b_{0}\left(\zeta-\frac{\varepsilon_{\alpha}}{2}\right)\right] \\
b_{0} & =\frac{1}{\sqrt{(1 / 2)\left(1+\varepsilon_{\alpha} / 2\right)^{2}-1}} .
\end{aligned}
$$

Function $v(\zeta)$ has a maximum at the midpoint of the interval of contact (denoted by $\zeta_{m}=\varepsilon_{\alpha} / 2$ ). We will do $v(\zeta)=0$ outside the interval of contact $0 \leq \zeta \leq \varepsilon_{\alpha}$.

Figure 3 shows the typical aspect of function $v(\zeta)$ for standard teeth. Note that, according to (9), the amplitude of $v(\zeta)$ has no influence on the load distribution, so a normalized function $v(\zeta)$, with a maximum value equal to 1 , may be considered for calculations, as one given by (11) and represented in Figure 3. According to this, the load sharing ratio for spur gears can be obtained by replacing (11) in (9), which yields the following result for transverse contact ratio $\varepsilon_{\alpha}$ between 1 and 2 :

$$
\begin{aligned}
& R(\zeta)=\frac{\cos \left[b_{0}\left(\zeta-\varepsilon_{\alpha} / 2\right)\right]}{\cos \left[b_{0}\left(\zeta-\varepsilon_{\alpha} / 2\right)\right]+\cos \left[b_{0}\left(\zeta+1-\varepsilon_{\alpha} / 2\right)\right]} \\
& \text { for } 0 \leq \zeta \leq \varepsilon_{\alpha}-1 \\
& R(\zeta)=1 \quad \text { for } \varepsilon_{\alpha}-1 \leq \zeta \leq 1 \\
& R(\zeta)=\frac{\cos \left[b_{0}\left(\zeta-\varepsilon_{\alpha} / 2\right)\right]}{\cos \left[b_{0}\left(\zeta-1-\varepsilon_{\alpha} / 2\right)\right]+\cos \left[b_{0}\left(\zeta-\varepsilon_{\alpha} / 2\right)\right]} \\
& \text { for } 1 \leq \zeta \leq \varepsilon_{\alpha}
\end{aligned}
$$

which has been represented in Figure 4(a). Similarly, the load sharing ratio for high contact ratio spur gears is given by

$$
\begin{aligned}
R(\zeta)= & \left(\cos \left[b_{0}\left(\zeta-\frac{\varepsilon_{\alpha}}{2}\right)\right]\right) \\
& \times\left(\cos \left[b_{0}\left(\zeta-\frac{\varepsilon_{\alpha}}{2}\right)\right]+\cos \left[b_{0}\left(\zeta+1-\frac{\varepsilon_{\alpha}}{2}\right)\right]\right. \\
& \left.+\cos \left[b_{0}\left(\zeta+2-\frac{\varepsilon_{\alpha}}{2}\right)\right]\right)^{-1}
\end{aligned}
$$

for $0 \leq \zeta \leq \varepsilon_{\alpha}-2$

$$
\begin{aligned}
R(\zeta)= & \left(\cos \left[b_{0}\left(\zeta-\frac{\varepsilon_{\alpha}}{2}\right)\right]\right) \\
\times & \quad \text { for } \varepsilon_{\alpha}-2 \leq \zeta \leq 1 \\
R(\zeta)= & \left(\cos \left[b_{0}\left(\zeta-\frac{\varepsilon_{\alpha}}{2}\right)\right]+\cos \left[b_{0}\left(\zeta+1-\frac{\varepsilon_{\alpha}}{2}\right)\right]\right)^{-1} \\
& \times\left(\cos \left[b_{0}\left(\zeta-1-\frac{\varepsilon_{\alpha}}{2}\right)\right]+\cos \left[b_{0}\left(\zeta-\frac{\varepsilon_{\alpha}}{2}\right)\right]\right. \\
& \left.\quad+\cos \left[b_{0}\left(\zeta+1-\frac{\varepsilon_{\alpha}}{2}\right)\right]\right)^{-1}
\end{aligned}
$$

for $1 \leq \zeta \leq \varepsilon_{\alpha}-1$

$$
\begin{aligned}
R(\zeta)= & \left(\cos \left[b_{0}\left(\zeta-\frac{\varepsilon_{\alpha}}{2}\right)\right]\right) \\
& \times\left(\cos \left[b_{0}\left(\zeta-1-\frac{\varepsilon_{\alpha}}{2}\right)\right]+\cos \left[b_{0}\left(\zeta-\frac{\varepsilon_{\alpha}}{2}\right)\right]\right)^{-1} \\
R(\zeta)= & \left(\cos \left[b_{0}\left(\zeta-\frac{\varepsilon_{\alpha}}{2}\right)\right]\right) \\
& \times\left(\cos \left[b_{0}\left(\zeta-2-\frac{\varepsilon_{\alpha}}{2}\right)\right]+\cos \left[b_{0}\left(\zeta-1-\frac{\varepsilon_{\alpha}}{2}\right)\right]\right. \\
& \left.\quad+\cos \left[b_{0}\left(\zeta-\frac{\varepsilon_{\alpha}}{2}\right)\right]\right)^{-1} \quad \text { for } 2 \leq \zeta \leq \varepsilon_{\alpha}
\end{aligned}
$$

which has been represented in Figure 4(b).

As seen in Figure 4, the load sharing ratio $R(\zeta)$ presents a linear variation with the profile parameter $\zeta$, with different slope at any interval, according to the number of teeth in 


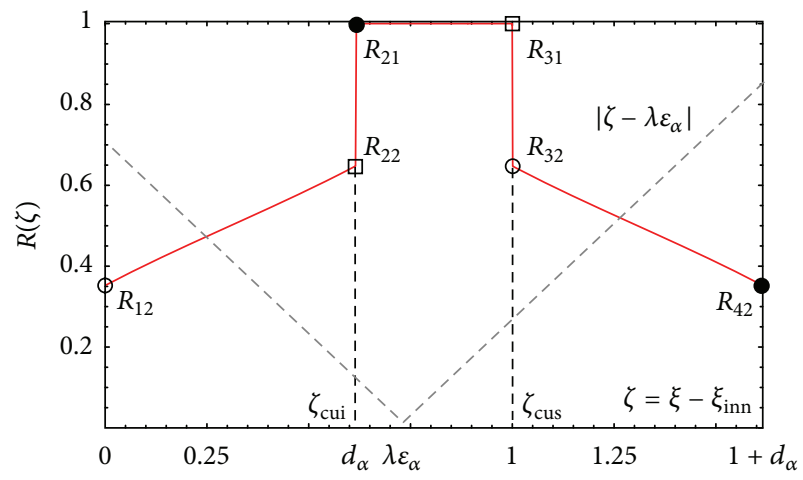

(a)

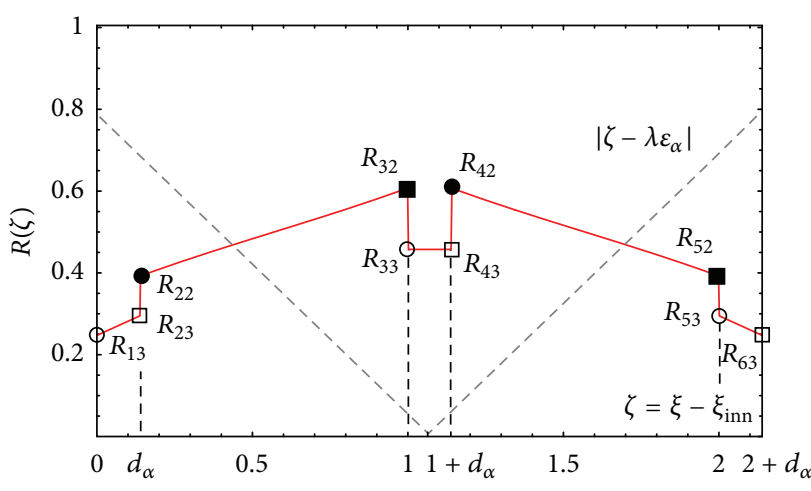

(b)

FIGURE 4: Typical shape of function $R(\zeta)$ : (a) for $1<\varepsilon_{\alpha}<2$; (b) for $2<\varepsilon_{\alpha}<3$.

simultaneous contact. The limits of each interval can be known from the fractional part of the transverse contact ratio, $d_{\alpha}$. The values of $R(\zeta)$ at the limits of these intervals depend on the contact ratio; however, this dependence is very slight for standard tooth height and center distance, and we can consider constant values to be used for any spur gear, as induced errors are very small $[24,26]$. For standard contact ratio gears, these constant values are

$$
R_{12} \approx R_{42} \approx 0.33, \quad R_{22} \approx R_{32} \approx 0.66, \quad R_{21}=R_{31}=1,
$$

while for high contact ratio gears,

$$
\begin{gathered}
R_{13} \approx R_{63} \approx 0.25, \quad R_{23} \approx R_{53} \approx 0.30, \quad R_{33} \approx R_{43} \approx 0.45, \\
R_{22} \approx R_{52} \approx 0.40, \quad R_{32} \approx R_{42} \approx 0.60 .
\end{gathered}
$$

The first subscript denotes the contact point; the second one the number of pairs in simultaneous contact. As the total load is constant, it is verified for $1<\varepsilon_{\alpha}<2$ :

$$
R_{12}+R_{32}=1, \quad R_{22}+R_{42}=1,
$$

and, for $2<\varepsilon_{\alpha}<3$,

$$
\begin{array}{cl}
R_{13}+R_{33}+R_{53}=1, & R_{23}+R_{43}+R_{63}=1, \\
R_{22}+R_{42}=1, & R_{32}+R_{52}=1 .
\end{array}
$$

According to this, the load sharing ratio for standard spur gears, given by (12), can be also computed from

$$
R(\zeta)= \begin{cases}\frac{1}{3}\left(1+\frac{\zeta}{\varepsilon_{\alpha}-1}\right) & \text { for } 0 \leq \zeta \leq \varepsilon_{\alpha}-1 \\ 1 & \text { for } \varepsilon_{\alpha}-1 \leq \zeta \leq 1 \\ \frac{1}{3}\left(1+\frac{\varepsilon_{\alpha}-\zeta}{\varepsilon_{\alpha}-1}\right) & \text { for } 1 \leq \zeta \leq \varepsilon_{\alpha}\end{cases}
$$

Similarly, the load sharing ratio for high contact ratio spur gears, given by (13), can be also computed from

$$
R(\zeta)= \begin{cases}0.25+\frac{0.05}{\varepsilon_{\alpha}-2} \zeta & \text { for } 0 \leq \zeta \leq \varepsilon_{\alpha}-2 \\ 0.40+\frac{0.20}{3-\varepsilon_{\alpha}}\left(\zeta-\varepsilon_{\alpha}+2\right) & \text { for } \varepsilon_{\alpha}-2 \leq \zeta \leq 1 \\ 0.45 & \text { for } 1 \leq \zeta \leq \varepsilon_{\alpha}-1 \\ 0.60-\frac{0.20}{3-\varepsilon_{\alpha}}\left(\zeta-\varepsilon_{\alpha}+1\right) & \text { for } \varepsilon_{\alpha}-1 \leq \zeta \leq 2 \\ 0.30-\frac{0.05}{\varepsilon_{\alpha}-2}(\zeta-2) & \text { for } 2 \leq \zeta \leq \varepsilon_{\alpha} .\end{cases}
$$

A study of the accuracy of the above presented model of load distribution for conventional spur gears can be found in $[25$, 26]. A wider study involving conventional and high contact ratio gears has been reported in [33]. In all the considered cases, accuracy of (12) and (13) for the load sharing ratio is high enough for strength and load capacity calculations.

\section{Model of Efficiency}

The transmitted energy from contact at the inner point of contact of a spur pinion tooth to contact at the same point of the next tooth (i.e., $\Delta \xi=\Delta \zeta=1$ ) is given by

$$
W_{u}=F_{b 1} \frac{2 \pi}{Z_{1}} .
$$

Similarly, the total mechanical (load-dependent) energy lost during a small rotation of the pinion can be expressed as the average friction coefficient $\mu$, multiplied by the normal load acting on the tooth and by the relative sliding. All these parameters depend on the contact point and consequently can be expressed as a function of $\xi$. References [27-29] present the development of the model for spur and helical gears. Following the same procedure we obtain for the energy loss [8],

$$
d W_{s}=\mu F R(\xi) \frac{r_{b 1}}{r_{b 2}}\left(r_{b 1}+r_{b 2}\right) \frac{2 \pi}{Z_{1}}\left|\tan \alpha_{t}^{\prime}-\frac{2 \pi}{Z_{1}} \xi\right| d \xi .
$$




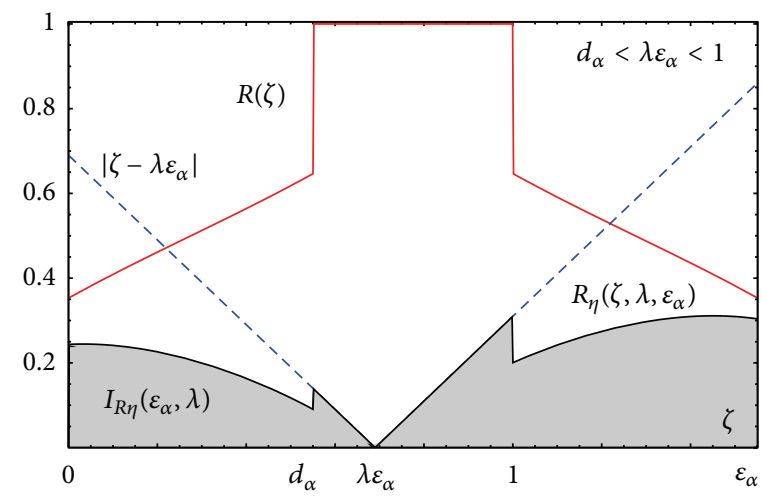

(a)

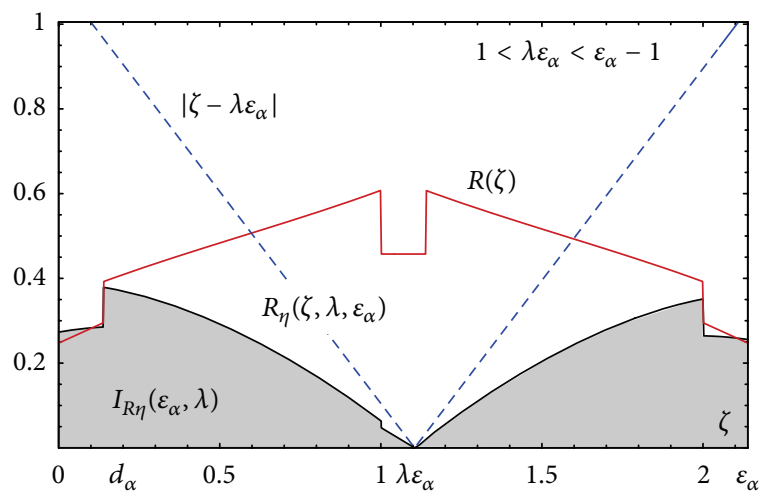

(b)

FIGURE 5: Function $R_{\eta}\left(\varepsilon_{\alpha}, \lambda, \zeta\right)$ : (a) conventional spur gear with $d_{\alpha} \leq \lambda \varepsilon_{\alpha} \leq 1$; (b) high contact ratio spur gear with $1 \leq \lambda \varepsilon_{\alpha} \leq \varepsilon_{\alpha}-1$.

Integrating along the complete meshing cycle and taking into account that the friction coefficient is assumed to be constant along the path of contact, we obtain

$$
W_{s}=\mu F \frac{r_{b 1}}{r_{b 2}}\left(r_{b 1}+r_{b 2}\right) \frac{2 \pi}{Z_{1}} \int_{\xi_{\mathrm{inn}}}^{\xi_{\mathrm{inn}}+\varepsilon_{\alpha}} R(\xi)\left|\tan \alpha_{t}^{\prime}-\frac{2 \pi}{Z_{1}} \xi\right| d \xi,
$$

and from (20) and (22) the following expression is obtained for the efficiency $\eta$ :

$$
\eta=1-\frac{W_{s}}{W_{u}}=1-\mu \frac{r_{b 1}+r_{b 2}}{r_{b 2}} \int_{\xi_{\text {inn }}}^{\xi_{\text {inn }}+\varepsilon_{\alpha}} R(\xi)\left|\tan \alpha_{t}^{\prime}-\frac{2 \pi}{Z_{1}} \xi\right| d \xi
$$

which can be written as a function of the gear ratio $n$, as

$$
\eta=1-\mu\left(1+\frac{1}{n}\right) \int_{\xi_{\text {inn }}}^{\xi_{\text {inn }}+\varepsilon_{\alpha}} R(\xi)\left|\tan \alpha_{t}^{\prime}-\frac{2 \pi}{Z_{1}} \xi\right| d \xi .
$$

Equation (24) may be simplified if expressed as a function of $\zeta$. Moreover, if $\varepsilon_{\alpha 1}$ is the contribution to the contact ratio of the approach interval (from contact at the inner point of contact to the operating pitch point) and $\lambda$ the ratio between $\varepsilon_{\alpha 1}$ and $\varepsilon_{\alpha}$

$$
\begin{gathered}
\varepsilon_{\alpha 1}=\frac{Z_{1}}{2 \pi} \tan \alpha_{t}^{\prime}-\xi_{\text {inn }}, \\
\lambda=\frac{\varepsilon_{\alpha 1}}{\varepsilon_{\alpha}}
\end{gathered}
$$

the efficiency will be given by

$$
\eta=1-2 \pi \mu\left(\frac{1}{Z_{1}}+\frac{1}{Z_{2}}\right) \int_{0}^{\varepsilon_{\alpha}} R(\zeta)\left|\zeta-\lambda \varepsilon_{\alpha}\right| d \zeta .
$$

Equation (26) has been obtained from an average friction coefficient, constant along the path of contact. For simplicity, we will denote the function under the integral as $R_{\eta}$ :

$$
R_{\eta}\left(\varepsilon_{\alpha}, \lambda, \zeta\right)=R(\zeta)\left|\zeta-\lambda \varepsilon_{\alpha}\right|
$$

Function $R_{\eta}\left(\varepsilon_{\alpha}, \lambda, \zeta\right)$ depends on three dimensionless variables and has the typical shape shown in Figure 5. The integral of $R_{\eta}$ will be denoted by $I_{R \eta}$ and it will depend on two dimensionless variables:

$$
I_{R \eta}\left(\varepsilon_{\alpha}, \lambda\right)=\int_{0}^{\varepsilon_{\alpha}} R_{\eta}\left(\varepsilon_{\alpha}, \lambda, \zeta\right) d \zeta
$$

According to this, the efficiency of spur gears is finally described by

$$
\eta=1-2 \pi \mu\left(\frac{1}{Z_{1}}+\frac{1}{Z_{2}}\right) I_{R \eta}\left(\varepsilon_{\alpha}, \lambda\right) .
$$

$I_{R \eta}$ is the area under curve $R_{\eta}$ in Figure 5 (grey area), and can be only computed by means of numerical integration techniques. From (23) and Figure 5, the interval of integration should be divided for numerical integration taking into account the different possible locations of the point $\zeta=$ $\lambda \varepsilon_{\alpha}$, belonging to the interval of two pair-tooth contact or belonging to the interval of single pair-tooth contact (for high transverse contact ratio gears, belonging to the interval of three pair-tooth contact or belonging to the interval of two pair-tooth contact).

The main problem is the calculation of $I_{R \eta}$. Once calculated, the efficiency can be immediately known with (29), but the mathematical problem is not simple. Fortunately, function $I_{R \eta}$ depends on two parameters only, which suggests the possibility to find an approximate, accurate enough equation for $I_{R \eta}\left(\varepsilon_{\alpha}, \lambda\right)$ suitable for calculations. Next section deals with the search of such approximate equation.

\section{Approximate Equation for Function $I_{R \eta}$}

4.1. Standard Spur Gears, $1 \leq \varepsilon_{\alpha} \leq 2$. For numerical calculation of the integral of $R_{\eta}\left(\varepsilon_{\alpha}, \lambda, \zeta\right)$, the interval [0, $\left.\varepsilon_{\alpha}\right]$ should be divided in three subintervals according to the three segments of $R(\zeta)$, and one of them should be divided in two ones due to the location of $\lambda \varepsilon_{\alpha}$. It should be taken into account if this point $\zeta=\lambda \varepsilon_{\alpha}$ is located inside the interval of singlepair tooth contact $d_{\alpha} \leq \lambda \varepsilon_{\alpha} \leq 1$, as the case represented in Figure 5(a), or inside any of two intervals of two-pair tooth 


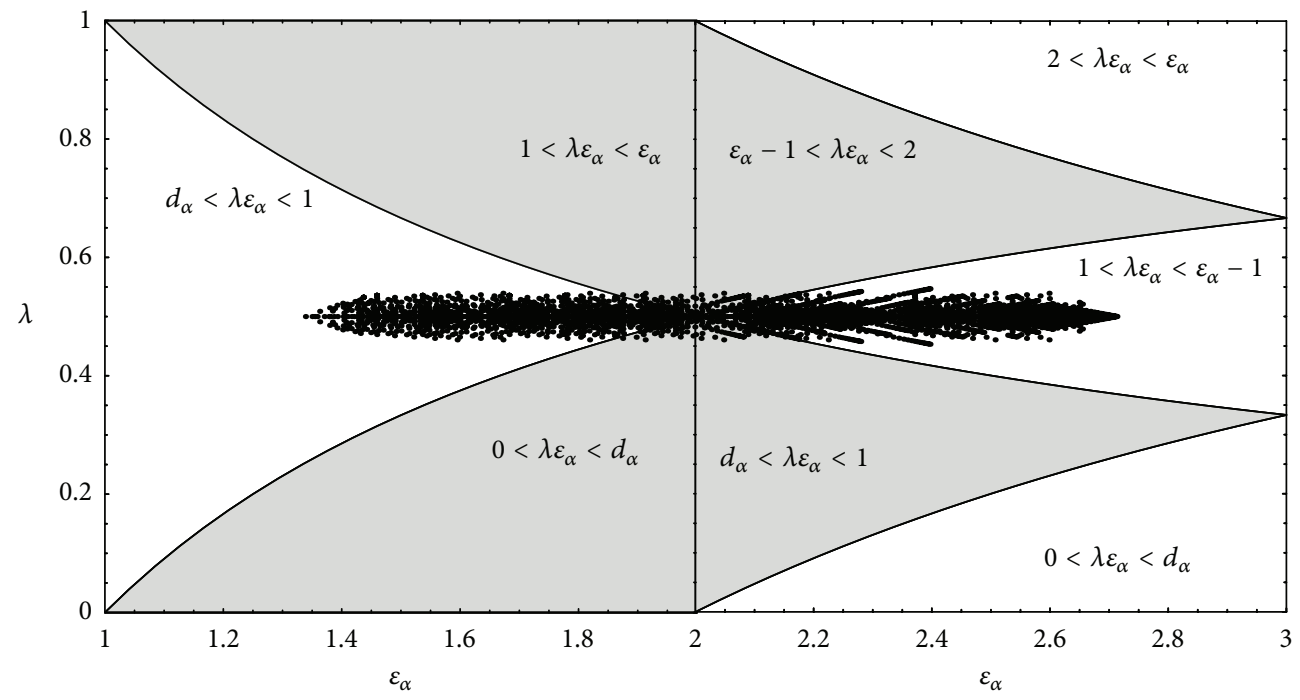

FIGURE 6: Domains of existence of $I_{R \eta}\left(\varepsilon_{\alpha}, \lambda\right)$ and numerical examples.

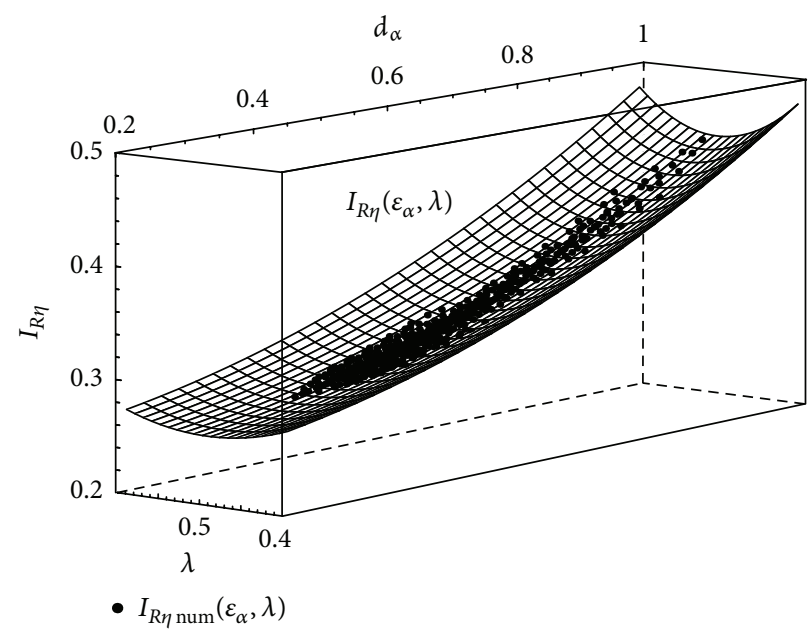

(a)

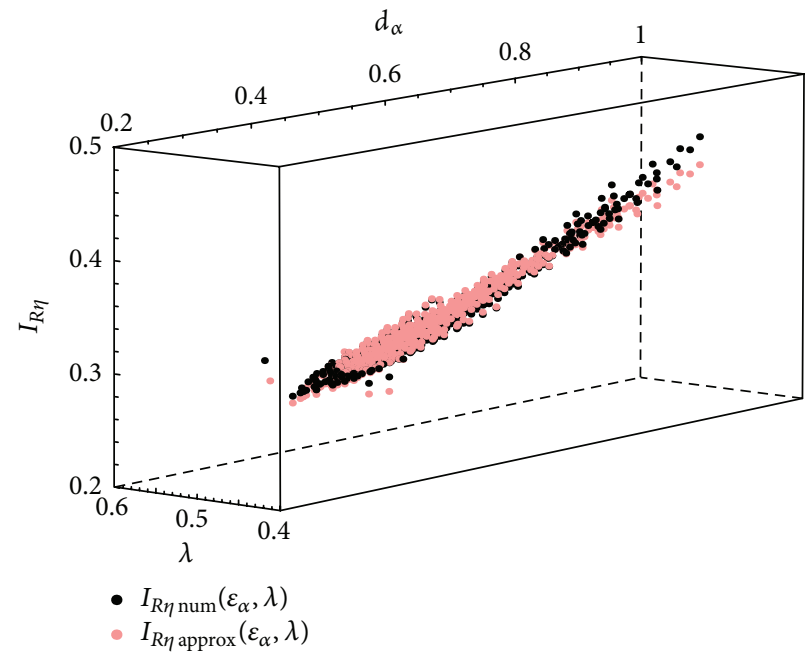

(b)

FIGURE 7: $I_{R \eta}\left(\varepsilon_{\alpha}, \lambda\right)$ for $1<\varepsilon_{\alpha}<2$ : (a) analytical and numerical values; (b) numerical and approximate values.

contact, $0 \leq \lambda \varepsilon_{\alpha} \leq d_{\alpha}$ or $1 \leq \lambda \varepsilon_{\alpha} \leq \varepsilon_{\alpha}$. However, as function $I_{R \eta}\left(\varepsilon_{\alpha}, \lambda\right)$ is symmetric respect to $\lambda=0.5$, the last two cases yield the same results. Figure 6 represents the domains of existence of three cases mentioned above, for theoretical ranges of values of $\lambda$ and $d_{\alpha}$.

Figure 6 also represents the values of $\varepsilon_{\alpha}$ and $\lambda$, for around one thousand different cases of spur gears with transverse contact ratio between 1 and 2, considering values of the design parameters inside wide enough ranges. It can be observed that all the obtained values of $\lambda$ are always contained in a thin interval around $\lambda=0.5 \pm 0.1$, which means the majority of the cases corresponding to $\lambda \varepsilon_{\alpha}$ inside the central interval of single-pair tooth contact, that is, $d_{\alpha} \leq \lambda \varepsilon_{\alpha} \leq 1$. Only for values of $\varepsilon_{\alpha}$ very close to $2, \lambda \varepsilon_{\alpha}$ may shift to the intervals of two-pair tooth contact, but this is less usual. According to this, the development of the model will be simplified by considering only the case $d_{\alpha} \leq \lambda \varepsilon_{\alpha} \leq 1$.

The limits of the four intervals of function $I_{R \eta}\left(\varepsilon_{\alpha}, \lambda\right)$ are known, as shown in Figure 5(a), as well as the equation of $R_{\eta}\left(\varepsilon_{\alpha}, \lambda, \zeta\right)$ in each interval, as seen in (18) and (27). Calculating the four integrals and the sum of all of them, a relatively simple analytic expression for $I_{R \eta}\left(\varepsilon_{\alpha}, \lambda\right)$ is obtained, which has been represented in Figure 7(a):

$$
I_{R \eta}\left(\varepsilon_{\alpha}, \lambda\right)=\frac{1}{2}+\frac{1}{2} d_{\alpha}(1-2 \lambda)^{2}-\lambda+\lambda^{2}+d_{\alpha}^{2}\left(\frac{4}{9}-\lambda+\lambda^{2}\right) \text {. }
$$

For unusual cases of spur gears with $0 \leq \lambda \varepsilon_{\alpha} \leq d_{\alpha}$ or $1 \leq \lambda \varepsilon_{\alpha} \leq \varepsilon_{\alpha}$ (always with $\varepsilon_{\alpha} \approx 2$ ) an analytic expression of 
function $I_{R \eta}\left(\varepsilon_{\alpha}, \lambda\right)$, similar to one given by (30) for the other case, could be obtained by following identical procedure.

The values of the load sharing ratio $R$ at singular points given by (14) are not exact, but they are slightly influenced by the fractional part of the contact ratio. This influence is not strong and however may induce a small error in the determination of $I_{R \eta}\left(\varepsilon_{\alpha}, \lambda\right)$. Obviously, (16) is always verified.

Nevertheless, it can be checked that the values of $I_{R \eta}\left(\varepsilon_{\alpha}, \lambda\right)$ represented in Figure 6 , which have been computed by means of numerical techniques, do fit accurately with function represented in Figure 7(a), which has been obtained from the analytic expression given by (30), for the considered range of values. The $R^{2}$-factor for the cases considered in the above mentioned study is greater than 0.9999 .

As said above, all the values of $I_{R \eta}\left(\varepsilon_{\alpha}, \lambda\right)$ are located in a very thin interval of $\lambda$, and accurate enough approximations of $I_{R \eta}\left(\varepsilon_{\alpha}, \lambda\right)$ can be obtained by considering only the influence of $\varepsilon_{\alpha}$ and neglecting the influence of $\lambda$. This can be observed in Figures 6 and 7, in which for a given value of $\varepsilon_{\alpha}$ the interval of values of $I_{R \eta}\left(\varepsilon_{\alpha}, \lambda\right)$-corresponding to the variation of $\lambda$-is very thin. According to that, the following linear approximation was obtained by linear correlation of the above thousand mentioned points:

$$
I_{R \eta \text { approx } 1}\left(\varepsilon_{\alpha}, \lambda\right) \approx I_{R \eta \text { approx } 1}\left(\varepsilon_{\alpha}\right)=\left(231 \varepsilon_{\alpha}-42\right) \cdot 10^{-3} .
$$

Of course, better accuracy is obtained if a parabolic correlation is used:

$$
\begin{aligned}
I_{R \eta \text { approx } 2}\left(\varepsilon_{\alpha}, \lambda\right) & \approx I_{R \eta \text { approx } 2}\left(\varepsilon_{\alpha}\right) \\
& =\left(231 \varepsilon_{\alpha}^{2}-503 \varepsilon_{\alpha}+537\right) \cdot 10^{-3}
\end{aligned}
$$

Figure 7(b) shows the comparison between the numerical values of function $I_{R \eta}\left(\varepsilon_{\alpha}, \lambda\right)$ computed by numerical integration and the values given by the linear approximation of (31). Relative errors of approximate values of $I_{R \eta}\left(\varepsilon_{\alpha}, \lambda\right)$ given by (31) are always included in the interval $\pm 2 \%$, as shown in Figure 8(a).

Errors are even lower if computed in terms of the efficiency. Figure 8(b) shows the relative error of the efficiency computed with the linear approximation of $I_{R \eta}\left(\varepsilon_{\alpha}, \lambda\right)$ given by (31). All of them are inside the interval $\pm 3 \cdot 10^{-4}( \pm 0.03 \%)$.

The parabolic approximation of $I_{R \eta}\left(\varepsilon_{\alpha}, \lambda\right)$, given by (32), yields even more accurate results. Relative errors of values of $I_{R \eta}\left(\varepsilon_{\alpha}, \lambda\right)$ are lower than $\pm 1 \%$, as shown in Figure 9(a). The relative errors in the estimation of the efficiency are reduced to $\pm 2 \cdot 10^{-4}( \pm 0.02 \%)$, as shown in Figure 9 (b).

4.2. High Contact Ratio Spur Gears, $2 \leq \varepsilon_{\alpha} \leq 3$. In this case, for numerical calculation of the integral of $R_{\eta}\left(\varepsilon_{\alpha}, \lambda, \zeta\right)$ the interval $\left[0, \varepsilon_{\alpha}\right]$ should be divided in five subintervals due to the five segments of $R(\zeta)$, and one of them should be divided in two ones due to the location of $\lambda \varepsilon_{\alpha}$. It should be taken into account if this point $\zeta=\lambda \varepsilon_{\alpha}$ is located inside one of three intervals of three-pair tooth contact $\left(0 \leq \lambda \varepsilon_{\alpha} \leq d_{\alpha}, 1 \leq \lambda \varepsilon_{\alpha} \leq\right.$ $\varepsilon_{\alpha}-1$ or $2 \leq \lambda \varepsilon_{\alpha} \leq \varepsilon_{\alpha}$ ) or inside one of two intervals of two-pair tooth contact $\left(d_{\alpha} \leq \lambda \varepsilon_{\alpha} \leq 1\right.$ or $\left.\varepsilon_{\alpha}-1 \leq \lambda \varepsilon_{\alpha} \leq 2\right)$.
Function $I_{R \eta}\left(\lambda, \varepsilon_{\alpha}\right)$ is symmetric with respect to $\lambda=0.5$, so the last two cases yield the same results, as well as the first and the third cases above.

Figure 6 represents the domains of existence of five cases mentioned above, for theoretical ranges of values of $\lambda$ and $d_{\alpha}$. Figure 6 also represents the values of $I_{R \eta}$ as a function of $d_{\alpha}$ and $\lambda$, for around one thousand different cases of spur gears with transverse contact ratio greater than 2 , considering wide enough ranges of values of the design parameters. The obtained values of $\lambda$ remain contained in the interval $\lambda=0.5 \pm 0.1$, which means that the majority of the cases corresponds to $\lambda \varepsilon_{\alpha}$ inside the central interval of three-pair tooth contact, that is, $1 \leq \lambda \varepsilon_{\alpha} \leq \varepsilon_{\alpha}-1$. As in the previous case, only in few cases, always for values of $\varepsilon_{\alpha}$ very close to 2 , $\lambda \varepsilon_{\alpha}$ may shift to the intervals of two-pair tooth contact, so the development of the model will be simplified by considering only the case $1 \leq \lambda \varepsilon_{\alpha} \leq \varepsilon_{\alpha}-1$.

The limits of the six intervals of function $I_{R \eta}\left(\varepsilon_{\alpha}, \lambda\right)$ are known as well as the equation of $R_{\eta}\left(\varepsilon_{\alpha}, \lambda, \zeta\right)$ in each interval. Calculating the six integrals and the sum of all of them, a relatively simple analytic expression for $I_{R \eta}\left(\varepsilon_{\alpha}, \lambda\right)$ is obtained:

$$
\begin{aligned}
& I_{R \eta \text { approx }}\left(\varepsilon_{\alpha}, \lambda\right) \approx I_{R \eta \text { approx }}\left(\varepsilon_{\alpha}\right) \\
& =\frac{1}{60}\left(55+34\left(\varepsilon_{\alpha}-2\right)\right. \\
& \left.\quad+11\left(\varepsilon_{\alpha}-2\right)^{2}-27 \varepsilon_{\alpha}^{2} \lambda+27 \varepsilon_{\alpha}^{2} \lambda^{2}\right) .
\end{aligned}
$$

In this case, the values of the load sharing ratio $R$ at singular points given by (15) are slightly more influenced by the fractional part of the contact ratio than those of the above case; however, the induced error in the determination of $I_{R \eta}\left(\varepsilon_{\alpha}, \lambda\right)$ is also very small. Obviously, (16) is always verified.

Also for high contact ratio spur gears, the thousand cases represented in Figure 6 are included in a thin interval of $\lambda$, so an approximate expression for $I_{R \eta}\left(\varepsilon_{\alpha}, \lambda\right)$ can be found as a function of $\varepsilon_{\alpha}$, neglecting the influence of $\lambda$. Furthermore, this variation with $\varepsilon_{\alpha}$ is practically linear, as shown in Figure 10(a). A very accurate approximation can be obtained by assuming a linear variation of $I_{R \eta}\left(\varepsilon_{\alpha}, \lambda\right)$ with $\varepsilon_{\alpha}$, with a value of the function of 0.45 for $d_{\alpha}=0$, and a value of 0.95 for $d_{\alpha}=1$. Accordingly,

$$
I_{R \eta}\left(\varepsilon_{\alpha}, \lambda\right) \approx I_{R \eta}\left(\varepsilon_{\alpha}\right)=\frac{1}{2} \varepsilon_{\alpha}-0.55
$$

which has been represented in Figure 10(b). Figure 10(a) shows how this expression fits with numerical values. Relative error in the evaluation of $I_{R \eta}\left(\varepsilon_{\alpha}, \lambda\right)$ is always smaller than $3 \%$, as shown in Figure 11(a). Relative error in the evaluation of the efficiency is always smaller than $0.03 \%$, as shown in Figure 11(b).

\section{Results}

5.1. Standard Spur Gears, $1 \leq \varepsilon_{\alpha} \leq 2$. Figure 12 represents the computed values of the efficiency for the set of thousand spur gears used in previous studies (Figures 6 to 9). Considered 


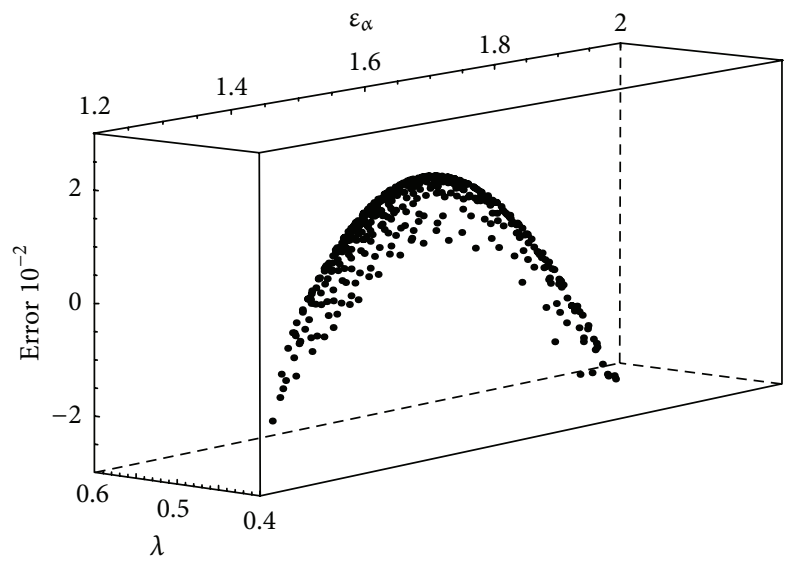

(a) $I_{R \eta \text { approxl }}$ : relative error $\left(\lambda, \varepsilon_{\alpha}\right)$

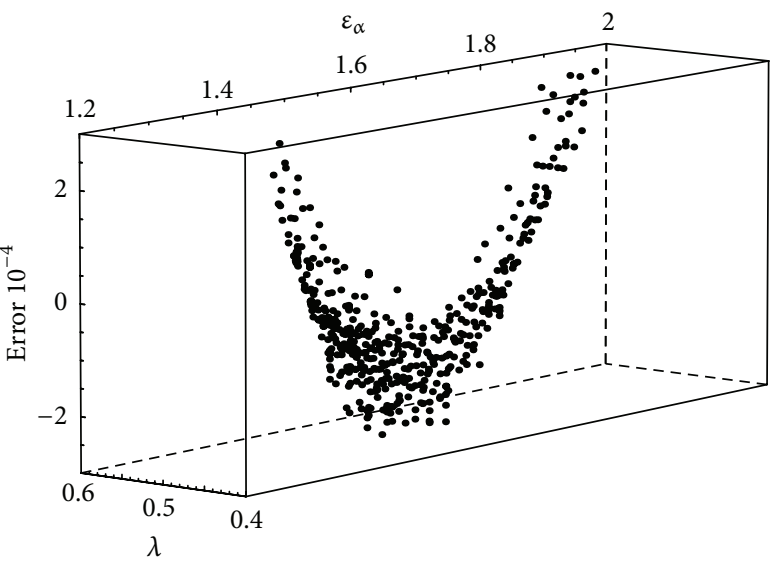

(b) $\eta_{\text {approxl }}$ : relative error $\left(\lambda, \varepsilon_{\alpha}\right)$

FIGURE 8: Relative error of linear approximation of function $I_{R \eta}\left(\varepsilon_{\alpha}, \lambda\right)$ : (a) in estimation of the function $I_{R \eta}\left(\varepsilon_{\alpha}, \lambda\right)$; (b) in estimation of the efficiency.

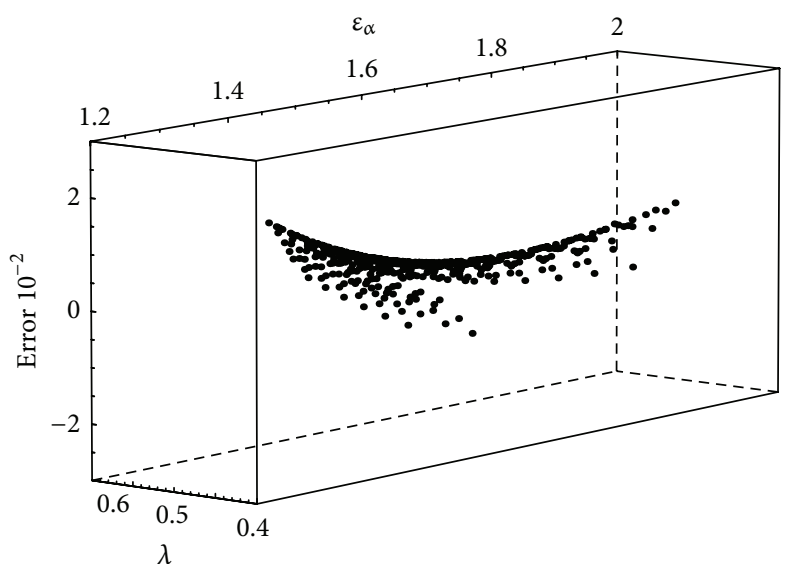

(a) $I_{R \eta \text { approx } 2}$ : relative error $\left(\lambda, \varepsilon_{\alpha}\right)$

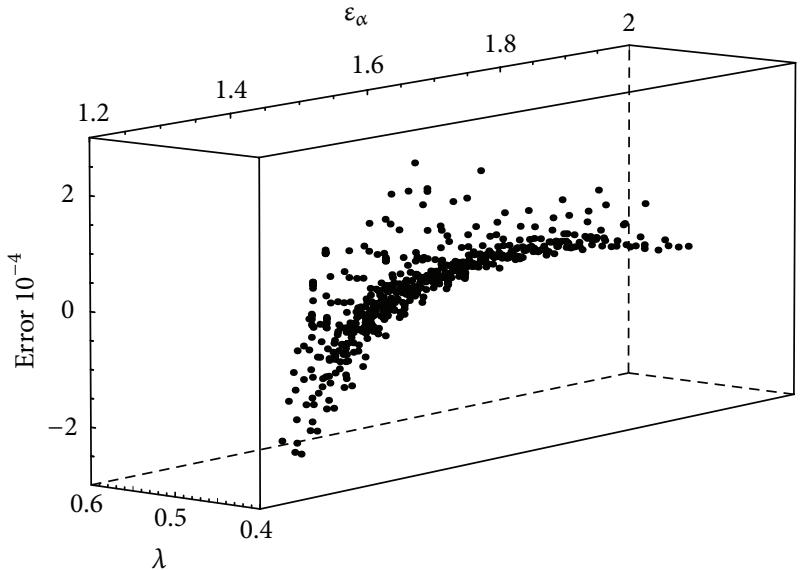

(b) $\eta_{\text {approx } 2}$ : relative error $\left(\lambda, \varepsilon_{\alpha}\right)$

FIGURE 9: Relative error of parabolic approximation of function $I_{R \eta}\left(\varepsilon_{\alpha}, \lambda\right)$ : (a) in estimation of the function $I_{R \eta}\left(\varepsilon_{\alpha}, \lambda\right)$; (b) in estimation of the efficiency.

data included standard pressure angle between $19 \mathrm{deg}$ and $27 \mathrm{deg}, 18$ to 30 tooth pinion, and gear ratio between 1 and 10. Addendum and dedendum took the values of the ISO and AGMA standard proportions $[34,35]$.

Values of the efficiency computed with the proposed analytical method are very close to those computed by numerical methods, yielding an error of $10^{-4}$ order, as shown in Figures 8(b) and 9(b). As said above, this small error is induced by the load sharing ratio function $R(\zeta)$, whose values at the singular points depend on the contact ratio. Nevertheless, an error of $10^{-4}$ order in the estimation of the efficiency is quite insignificant. Error levels in the estimation of $I_{R \eta}\left(\varepsilon_{\alpha}, \lambda\right)$ increase a little, but they are never higher than $2 \%$.

The influence on the friction losses and the efficiency of the number of teeth on pinion and wheel, as well as of the normal pressure angle, has been also studied. Results have been represented in Figure 13.

Results obtained from the proposed analytical method have been also compared with those obtained by assuming the load to be uniformly distributed along the line of contact, that is, considering $50 \%$ of the load acting at each pair of teeth along the intervals of double tooth contact and $100 \%$ of the load along the interval of single tooth contact. The proposed model yields slightly greater values of the efficiency. In fact, the relative sliding is bigger at points far from the pitch circle and the load is significantly smaller at those points, so computed friction losses are lower. Although the differences are not important when computed in terms of the efficiency (around $0.2 \%-0.4 \%$ ), they are much more significant when expressed in terms of losses (up to 11\%), as represented in Figure 14. 


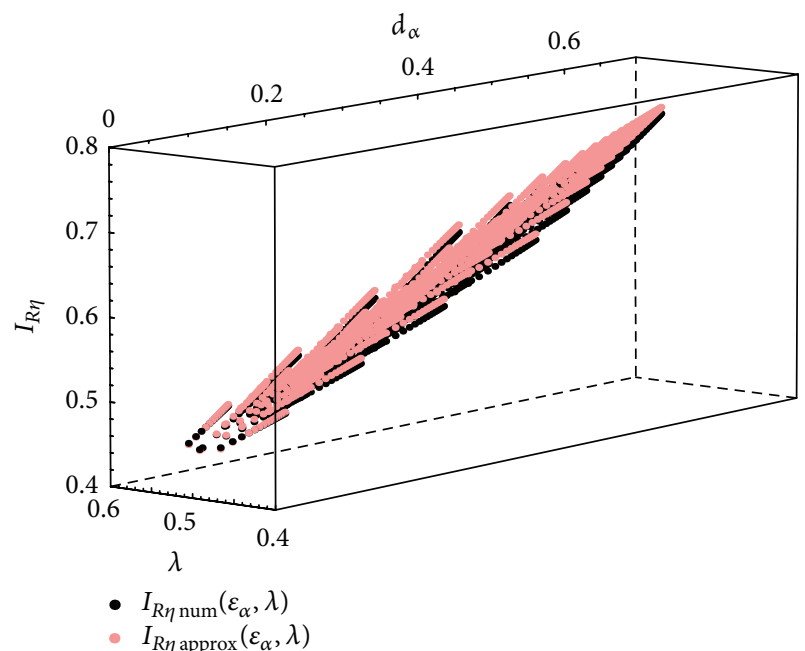

(a)

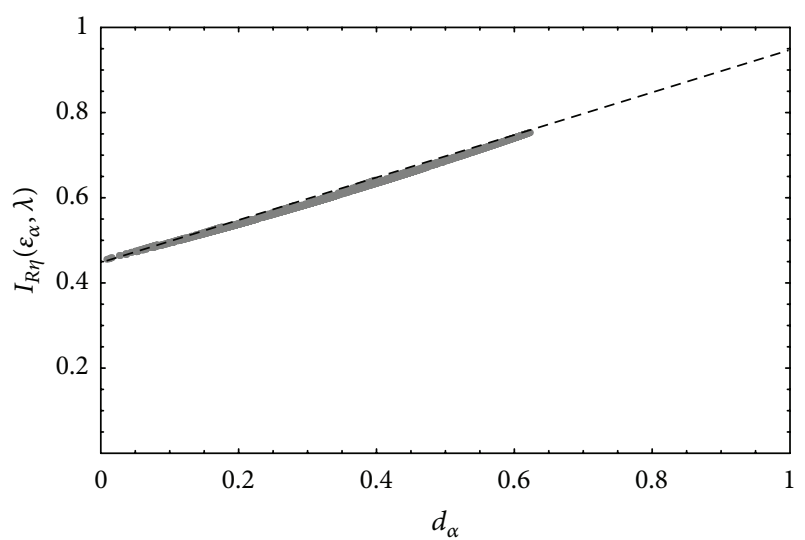

$\begin{array}{cl}- & I_{R \eta \text { num }}\left(\varepsilon_{\alpha}, \lambda\right) \\ --- & I_{R \eta \text { approx }}\left(\varepsilon_{\alpha}, \lambda\right)=\frac{1}{2} \varepsilon_{\alpha}-0.55\end{array}$

(b)

FIGURE 10: Numerical and approximate values of $I_{R \eta}\left(\varepsilon_{\alpha}, \lambda\right)$ for $2<\varepsilon_{\alpha}<3$.

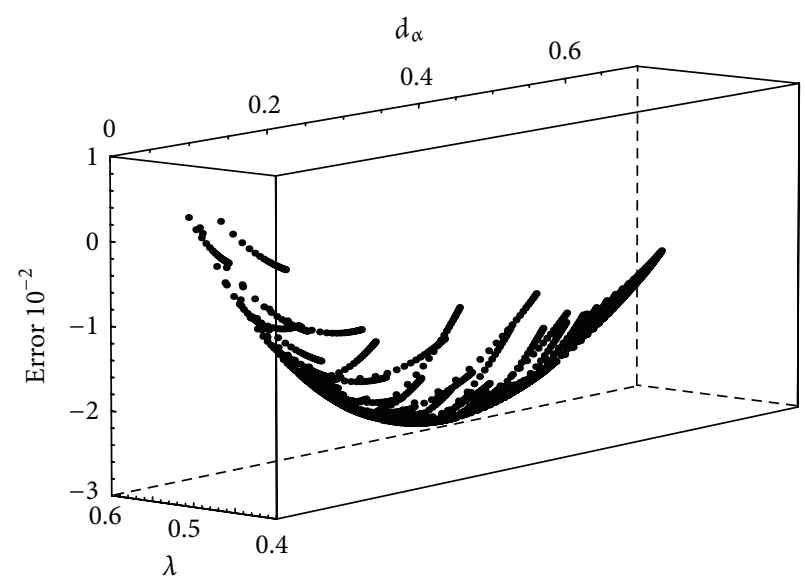

(a) $I_{R \eta \text { approx } 3}$ : relative error $\left(\lambda, \varepsilon_{\alpha}\right)$

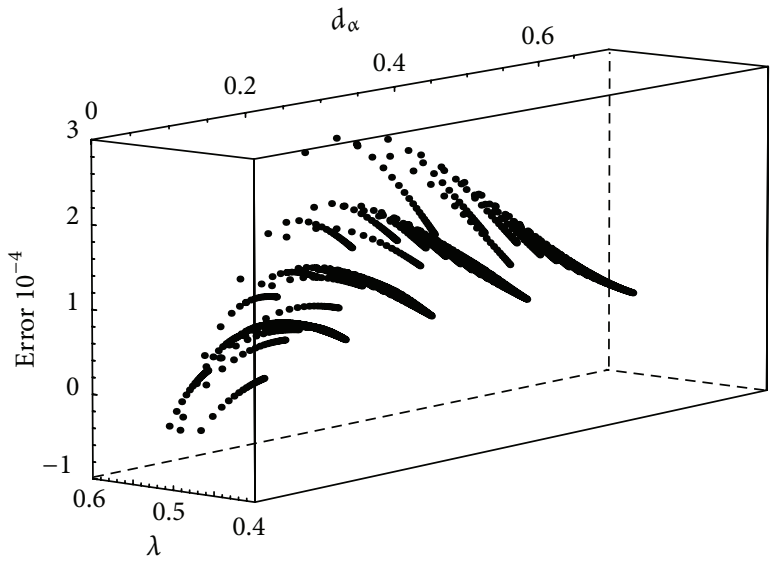

(b) $\eta_{\text {approx3 }}$ : relative error $\left(\lambda, \varepsilon_{\alpha}\right)$

FIGURE 11: Relative error of approximation of function $I_{R \eta}\left(\varepsilon_{\alpha}, \lambda\right)$ for $2<\varepsilon_{\alpha}<3$ : (a) in estimation of the function $I_{R \eta}\left(\varepsilon_{\alpha}, \lambda\right)$; (b) in estimation of the efficiency.

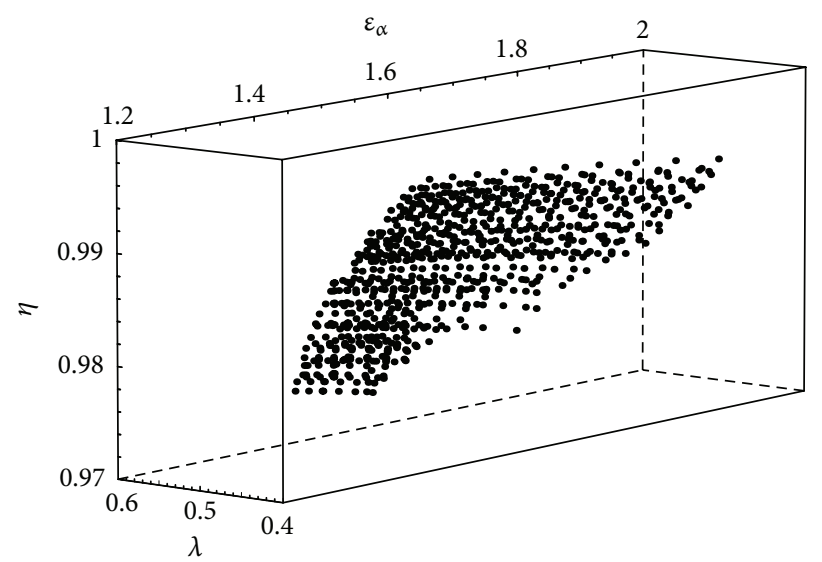

FIGURE 12: Values of the efficiency $\eta\left(\varepsilon_{\alpha}\right)$. 


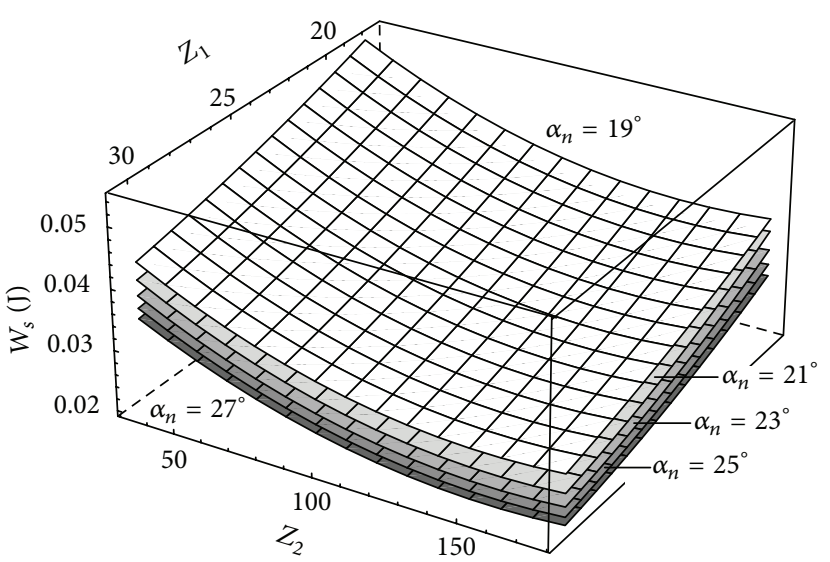

(a)

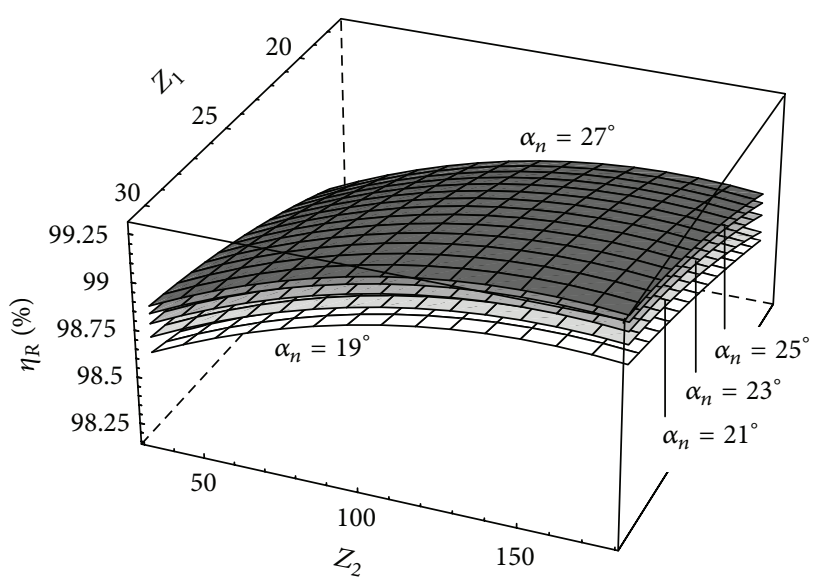

(b)

FIGURE 13: Influence of pressure angle and number of teeth on pinion and wheel: (a) on friction losses; (b) on the efficiency.

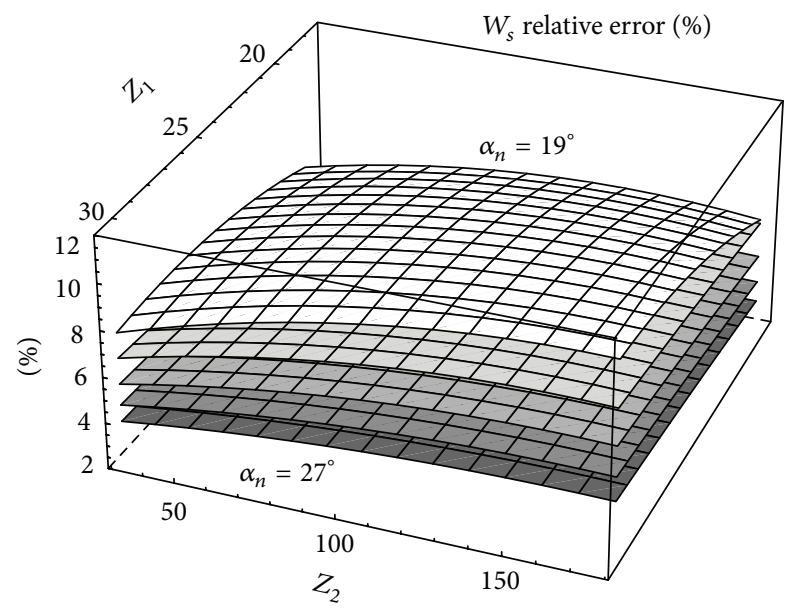

FIgURE 14: Percentage difference in the estimation of power losses with uniform and minimum elastic potential load distribution models.

5.2. High Contact Ratio Spur Gears, $2 \leq \varepsilon_{\alpha} \leq 3$. Figure 15 represents the computed values of the efficiency for a significant range of high transverse contact ratio spur gears. To get transverse contact ratio greater than 2 , spur gears were considered with standard pressure angle between 14 deg and $17 \mathrm{deg}, 50$ tooth pinion, and gear ratio between 1 and 4 . Addendum and dedendum took the values of the ISO and AGMA standard proportions [34, 35].

Values of the efficiency computed with the proposed analytical method are very close to those computed by numerical methods, yielding an error of $10^{-4}$ order. As in the previous case, this small error is induced by the singular points of the load sharing ratio function $R(\zeta)$. Errors in the estimation of the efficiency remain at similar levels of $10^{-4}$ order, while errors in the estimation of $I_{R \eta}\left(\varepsilon_{\alpha}, \lambda\right)$ increase a little, but never above 3\%.

Also for this case, the influence of the number of teeth on both gears and the normal pressure angle on the friction

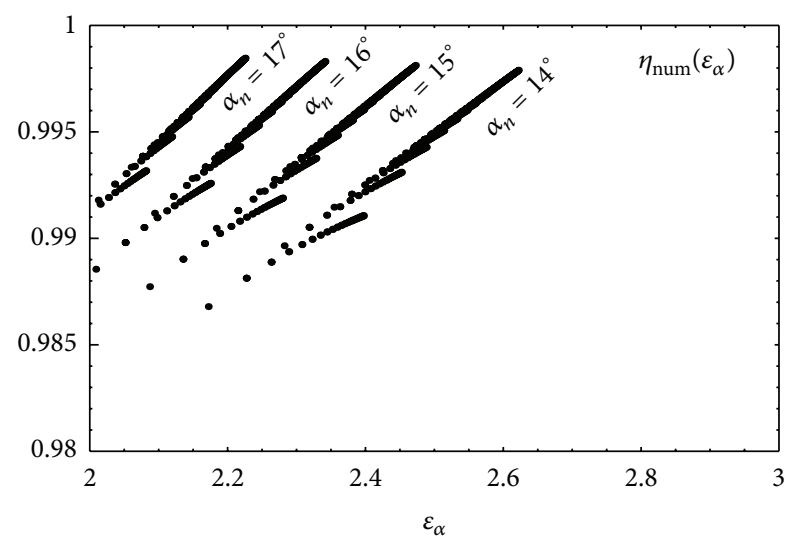

FIGURE 15: Computed values of the efficiency $\eta\left(\varepsilon_{\alpha}\right)$.

losses and the efficiency have been studied. Results have been represented in Figure 16.

Results obtained from the proposed analytical model have been also compared with those obtained by assuming the load to be uniformly distributed along the line of contact, that is, considering $1 / 3$ of the load acting at each pair of teeth along the intervals of three-pair tooth contact and $1 / 2$ of the load along the intervals of two-pair tooth contact. The proposed model yields slightly greater values of the efficiency. The relative sliding is bigger at points far from the pitch circle and the load is significantly smaller at those points, so friction losses are lower. Once again, differences are not important when computed in terms of efficiency (around $0.3 \%$ ) but in this case are much more significant when expressed in terms of losses (up to 50\%). The representation of these significant differences of computed losses as a function of the parameter $\left[1 / Z_{1}+1 / Z_{2}\right]^{-1}$ and the transverse contact ratio $\varepsilon_{\alpha}$ may be interesting. It is given in Figure 17, both for standard and high contact ratio spur gears. 


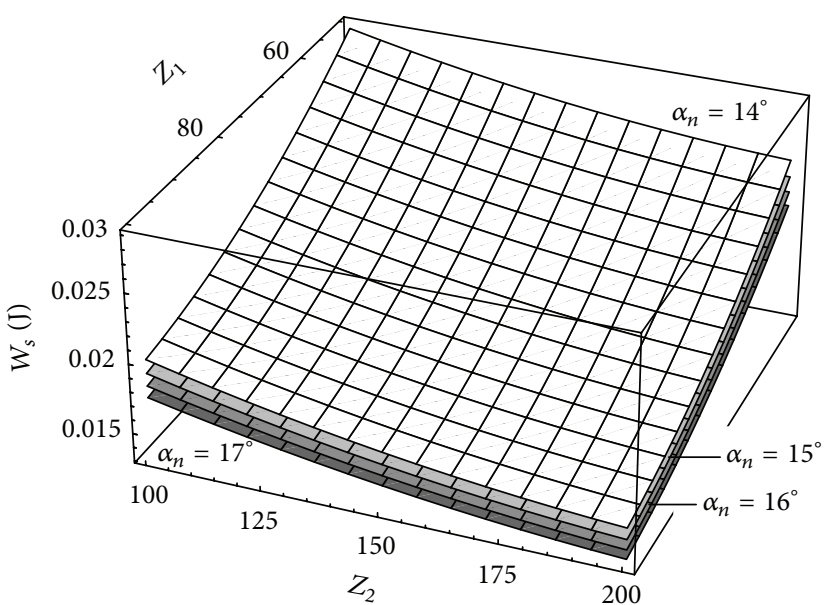

(a)

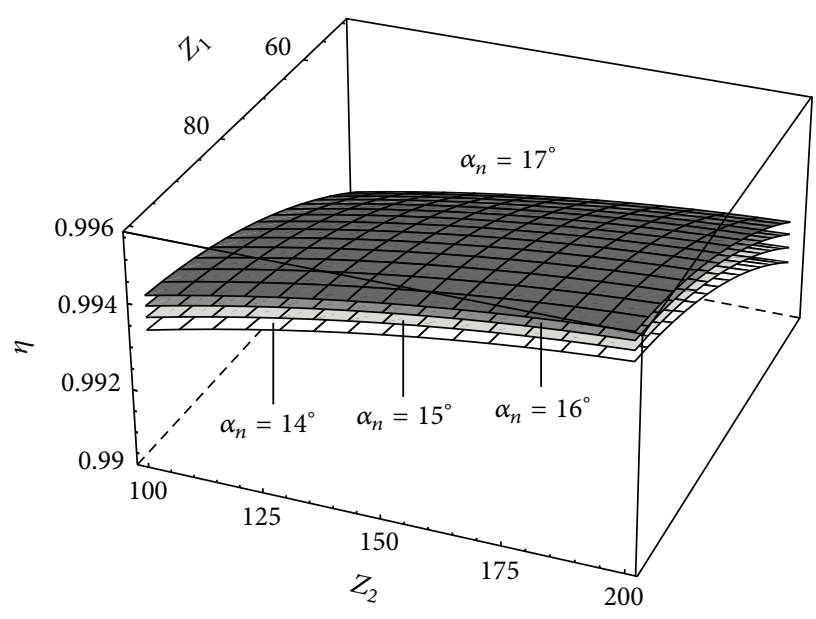

(b)

FIGURE 16: Influence of pressure angle and number of teeth on pinion and wheel: (a) on friction losses; (b) on the efficiency.

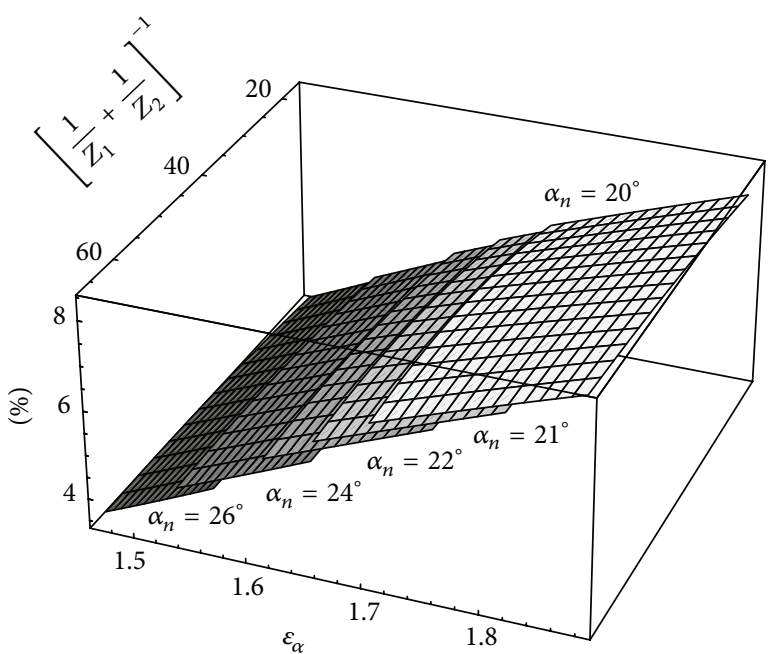

(a) Energy loss, $W_{s}(v=$ cte, $\mu=$ cte $)$ versus $W_{s}(v \neq$ cte, $\mu=$ cte $)$ : relative error

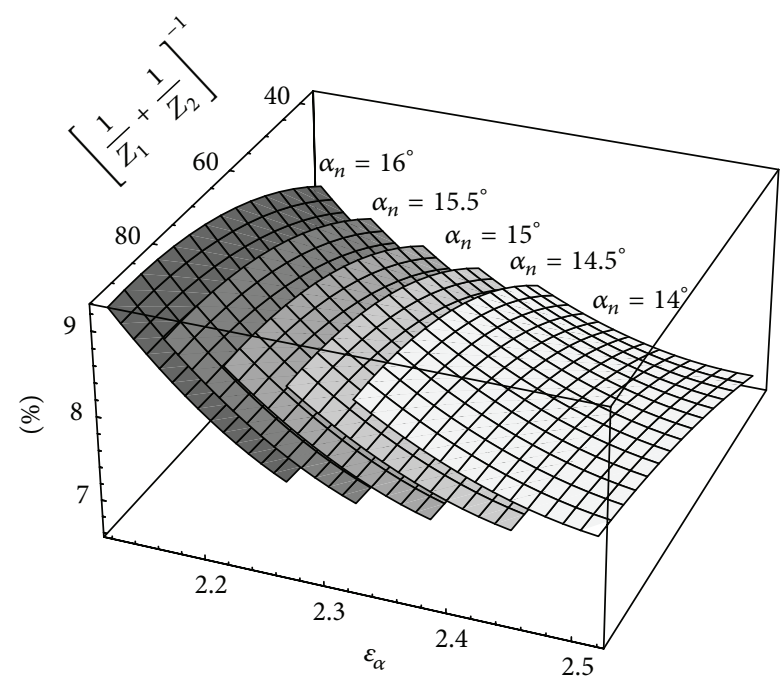

(b) Energy loss, $W_{s}(v=$ cte, $\mu=$ cte $)$ versus $W_{s}(\nu \neq$ cte, $\mu=$ cte $)$ : relative error

FIGURE 17: Percentage difference in the estimation of power losses with uniform and minimum elastic potential load distribution models: (a) standard spur gears; (b) high contact ratio spur gears.

\section{Conclusions}

A model of efficiency for involute spur gears has been developed from a nonuniform load sharing model, based on the minimum elastic potential criterion and assuming the friction coefficient to be constant along the path of contact. Both standard and high contact ratio spur gears have been considered. According to the obtained load sharing ratio, the efficiency has been expressed by a very simple, analytic equation, as a function of the average friction coefficient, the number of teeth on pinion and wheel, and the transverse contact ratio.

In spite of its simplicity, this expression allows to compute the efficiency with very small errors, always lower than $0.0003(0.03 \%$ relative error $)$, if compared with numerical calculations, for a wide range of geometric and operating parameters. In all the cases, values of the efficiency are higher than those obtained from the hypothesis of uniform load sharing due to the lower load intensity at points with bigger relative sliding.

Some studies of the influence on the efficiency of several design parameters have been carried out. It can be checked that the efficiency increases for bigger pressure angle, for balanced specific sliding on pinion and wheel, also if the gear ratio decreases by increasing the number of teeth on pinion. These results are suitable for spur gears with contact ratio between 1 and 2.7 .

The presented model establishes the background of advanced models considering undercut teeth and vacuum 
gearing effects, variable friction coefficient along the path of contact, and not load-dependent losses.

\section{Nomenclature}

Symbols

$b$ : Face width $(\mathrm{m})$

$d_{\alpha}$ : Fractional part of $\varepsilon_{\alpha}$

E: Modulus of elasticity $\left(\mathrm{N} / \mathrm{m}^{2}\right)$

$e$ : Tooth chordal thickness (m)

$F$ : $\operatorname{Normal}$ load (N)

$f$ : Load per unit of length $(\mathrm{N} / \mathrm{m})$

$G$ : Transverse modulus of elasticity $\left(\mathrm{N} / \mathrm{m}^{2}\right)$

n: Gear ratio

$R$ : Load sharing ratio

$r_{b}$ : Base radius $(\mathrm{m})$

$r_{\xi}:$ Contact point radius $(\mathrm{m})$

$U$ : Elastic potential of the pair of teeth $(\mathrm{J})$

$v$ : Inverse unitary potential $\left(\mathrm{N} / \mathrm{m}^{2}\right)$

$W_{s}$ : Energy lost by friction (J)

$W_{u}$ : Transmitted energy $(\mathrm{J})$

$y$ : Coordinate along the tooth centerline from the gear rotation center $(\mathrm{m})$

$Z$ : Number of teeth

$\alpha_{C}:$ Load angle (rad)

$\alpha_{n}:$ Standard pressure angle (rad)

$\alpha_{t}^{\prime}$ : Operating transverse pressure angle ( $\left.\mathrm{rad}\right)$

$\varepsilon_{\alpha}$ : Transverse contact ratio

$\varepsilon_{\alpha 1}$ : Contact ratio corresponding to the approach interval

$\eta: \quad$ Efficiency

$\theta: \quad$ Involute rotation angle $(\mathrm{rad})$

$\lambda$ : Ratio between $\varepsilon_{\alpha 1}$ and $\varepsilon_{\alpha}$

$\mu$ : Average friction coefficient

$\xi$ : $\quad$ Profile parameter

$\zeta: \quad$ Auxiliary parameter.

\section{Subscripts}

1/2: Pinion/wheel

inn: Inner point of contact.

\section{Conflict of Interests}

The authors declare that a conflict of interest is not possible as they do not receive any financial support from MATHEMATICA company.

\section{Acknowledgment}

Thanks are expressed to the Spanish Council for Scientific and Technological Research for the support of the projects DPI2008-05787, "Calculation models for special cylindrical gears", and DPI2011-27661, "Advanced models for strength calculations and dynamic analysis of nonconventional cylindrical gears."

\section{References}

[1] H. E. Merritt and H. E., Gears, Sir Isaac Pitman \& Sons, London, UK, 1946.

[2] E. Buckingham, Analytical Mechanics of Gears, McGraw-Hill, New York, NY, USA, 1949.

[3] G. Niemman and H. Winter, Maschineelement, vol. 2, Springer, Berlin, Germany, 1989.

[4] T. Yada, "Review of gear efficiency equation and force treatment," JSME International Journal C, vol. 40, no. 1, pp. 1-8, 1997.

[5] G. Henriot, Engrenages. Conception, Fabrication, Mise en Oeuvre, Dunod, Paris, France, 7 edition, 1999.

[6] Y. Michlin and V. Myunster, "Determination of power losses in gear transmissions with rolling and sliding friction incorporated," Mechanism and Machine Theory, vol. 37, no. 2, pp. 167174, 2002.

[7] B. R. Höhn, K. Michaelis, and A. Wimmer, "Low loss gears," AGMA Technical Paper 05FTM11, AGMA, 2005.

[8] J. I. Pedrero, M. Estrems, and A. Fuentes, "Determination of the efficiency of cylindric gear sets," in Proceedings of the 4th World Congress on Gearing and Power Transmissions, Paris, France, 1999.

[9] N. E. Anderson, S. H. Loewental, and J. D. Black, "An analytical method to predict efficiency of aircraft gearboxes," NASA Technical Memorandum 83716, NASA, 1984.

[10] N. E. Anderson and S. H. Loewenthal, "Effect of geometry and operating conditions on spur gear system power loss," Journal of mechanical design, vol. 103, no. 4, pp. 151-159, 1981.

[11] N. E. Anderson and S. H. Loewenthal, "Efficiency of nonstandard and high contact ratio involute spur gears," Journal of Mechanisms, Transmissions, and Automation in Design, vol. 108, no. 1, pp. 119-126, 1986.

[12] M. Vaishya and D. R. Houser, "Modeling and measurement of sliding friction for gear analysis," AGMA Technical Paper 99FTMS1, AGMA, 1999.

[13] A. Lehtovaara, "Calculation of sliding power loss in spur gear contacts," Tribotest Journal, vol. 9, no. 1, pp. 23-34, 2002.

[14] Y. Diab, F. Ville, and P. Velex, "Prediction of power losses due to tooth friction in gears," Tribology Transactions, vol. 49, no. 2, pp. 266-276, 2006.

[15] K. F. Martin, “The efficiency of involute spur gears," Journal of mechanical design, vol. 103, no. 4, pp. 160-169, 1981.

[16] S. Wu and H. S. Cheng, "Friction model of partial-EHL contacts and its application to power loss in spur gears," Tribology Transactions, vol. 34, no. 3, pp. 398-407, 1991.

[17] $\mathrm{H} . \mathrm{Xu}$, Development of a generalized mechanical efficiency prediction methodology for for gear pairs [M.S. thesis], The Ohio State University, Columbus, Ohio, USA, 2005.

[18] J. Coy, A. Mitchell, and B. Hamrock, "Transmission efficiency measurements and correlations with physical characteristics of the lubricant," NASA Technical Memorandum ADA149179, NASA, 1984.

[19] C. Naruse, S. Haizuka, R. Nemoto, and K. Kurokawa, "Studies on frictional loss, temperature rise and limiting load for scoring of spur gears," Bulletin of the JSME, vol. 29, no. 248, pp. 600-608, 1986.

[20] M. Yoshizaki, G. Naruse, R. Nemoto, and S. Haizuka, "Study on frictional loss of spur gears (concerning the influence of tooth form, load, tooth surface roughness, and lubricating oil)," Tribology Transactions, vol. 34, no. 1, pp. 138-146, 1991. 
[21] T. T. Petry-Johnson, Experimental investigation of spur gear efficiency [M.S. thesis], The Ohio State University, Columbus, Ohio, USA, 2007.

[22] T. T. Petry-Johnson, A. Kahraman, N. E. Anderson, and D. R. Chase, "An experimental investigation of spur gear efficiency," Journal of Mechanical Design, vol. 130, no. 6, Article ID 062601, 10 pages, 2008.

[23] P. Velex and F. Ville, "An analytical approach to tooth friction losses in spur and helical gears-influence of profile modifications," Journal of Mechanical Design, vol. 131, no. 10, Article ID 101008, 10 pages, 2009.

[24] J. I. Pedrero, M. Artés, and A. Fuentes, "Modelo de distribución de carga en engranajes cilíndricos de perfil de evolvente," Revista Iberoamericana de Ingeniería Mecánica, vol. 3, no. 1, pp. 31-44, 1999.

[25] J. I. Pedrero, M. Pleguezuelos, M. Artés, and J. A. Antona, "Load distribution model along the line of contact for involute external gears," Mechanism and Machine Theory, vol. 45, no. 5, pp. 780794, 2010.

[26] M. B. Sánchez, M. Pleguezuelos, and J. I. Pedrero, "Enhanced model of load distribution along the line of contact for nonstandard involute external gears," Meccanica, vol. 48, no. 3, pp. 527-543, 2013.

[27] M. Pleguezuelos, Modelo de distribución de carga en engranajes cilíndricos de perfil de evolvente [Tesis Doctoral], Universidad Nacional de Educación a Distancia, UNED, Madrid, Spain, 2006.

[28] J. I. Pedrero, M. Pleguezuelos, and M. Muñoz, "Simplified calculation method for the efficiency of involute spur gears," in Proceedings of the ASME International Design Engineering Technical Conferences \& Computers and Information in Engineering Conference (IDETC/CIE '09), San Diego, Calif, USA, August 2009.

[29] J. I. Pedrero, M. Pleguezuelos, and M. B. Sanchez, "Model of efficiency of high transverse contact ratio spur gears," in Proceedings of the JSME International Conference on Motion and Power Transmissions, Sendai, Japan, 2009.

[30] M. Pleguezuelos, J. I. Pedrero, and M. B. Sánchez, "Simplified calculation method for the efficiency of involute helical gears," in New Trends in Mechanism Science, Springer, Berlin, Germany, 2010.

[31] M. Pleguezuelos, J. I. Pedrero, and M. B. Sánchez, "Analitycal model of the efficiency of spur gears: study of the influence of the design parameters," in Proceedings of the ASME International Design Engineering Technical Conferences \& Computers and Information in Engineering Conference (IDETC/CIE '11), Washington, DC, USA, 2011.

[32] Wolfram Research, Mathematica, Version 7.0, Wolfram Research, Champaign, Ill, USA, 2008.

[33] M. B. Sánchez, Modelo de cálculo resistente de engranajes cilíndricos de alto grado de recubrimiento [Tesis Doctoral], Universidad Nacional de Educación a Distancia, UNED, Madrid, Spain, 2013.

[34] AGMA, "Tooth proportions for fine-pitch spur and helical gears," AGMA Standard 1003-H07, American Gear Manufacturers Association, Alexandria, Va, USA, 2007.

[35] ISO, "Cylindrical gears for general and heavy engineeringstandard basic rack tooth profile," ISO Standard 53, International Organization for Standardization, Geneva, Switzerland, 1998. 


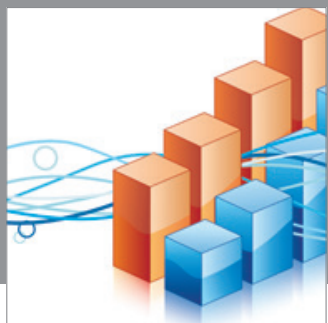

Advances in

Operations Research

mansans

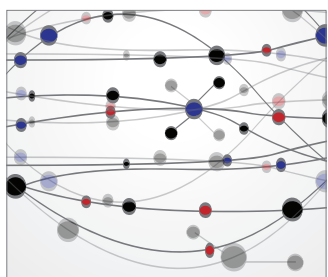

The Scientific World Journal
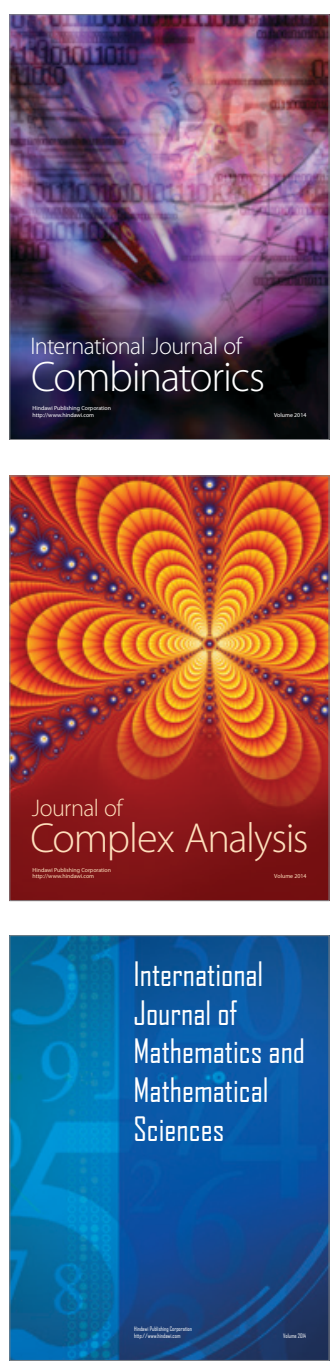
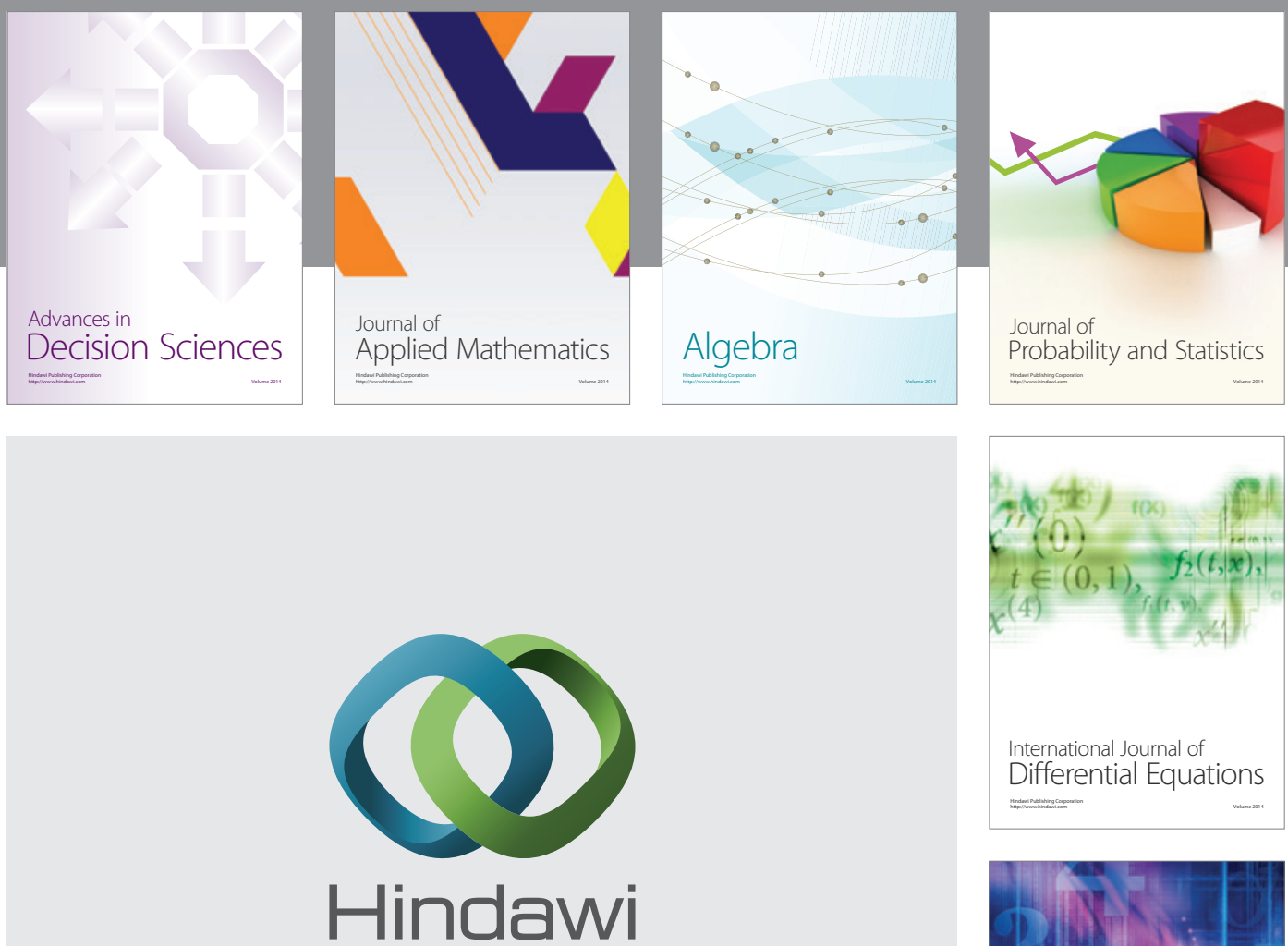

Submit your manuscripts at http://www.hindawi.com
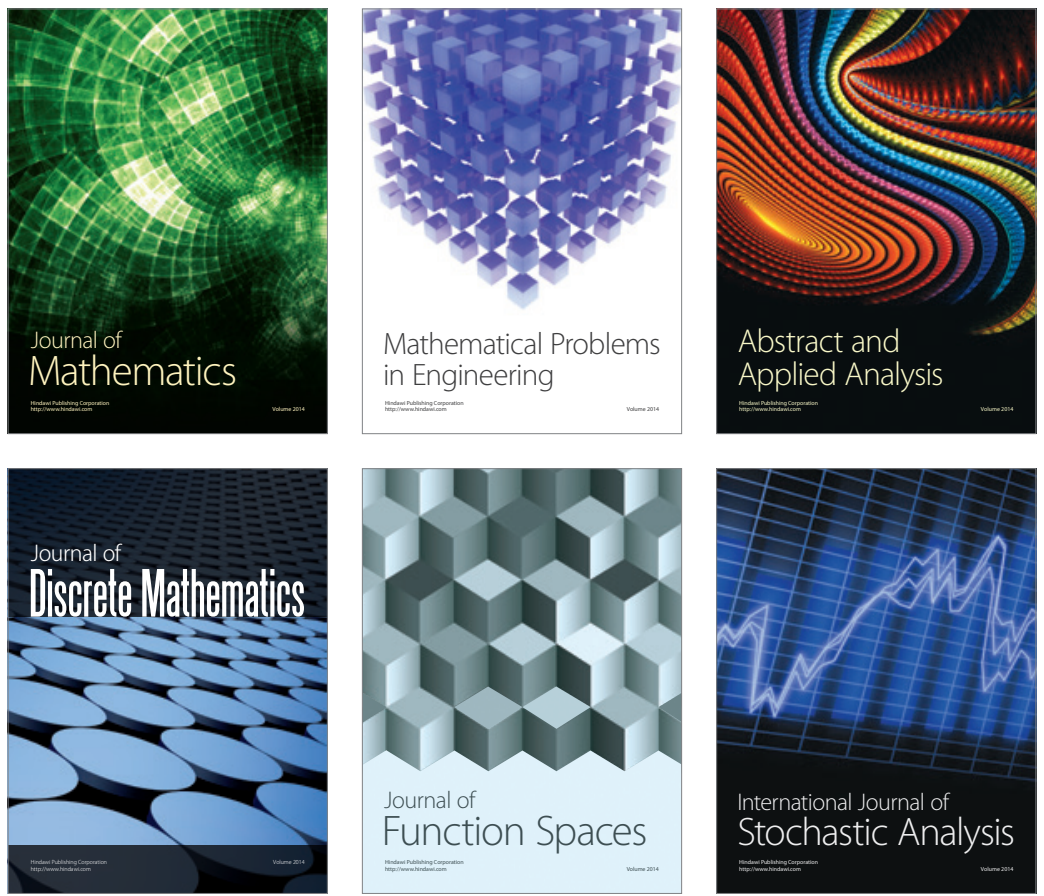

Journal of

Function Spaces

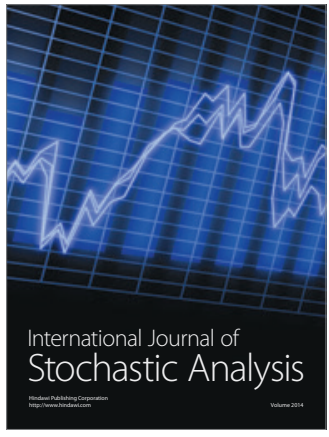

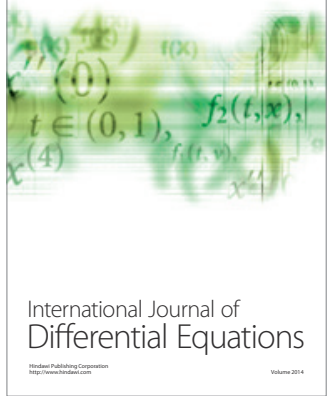
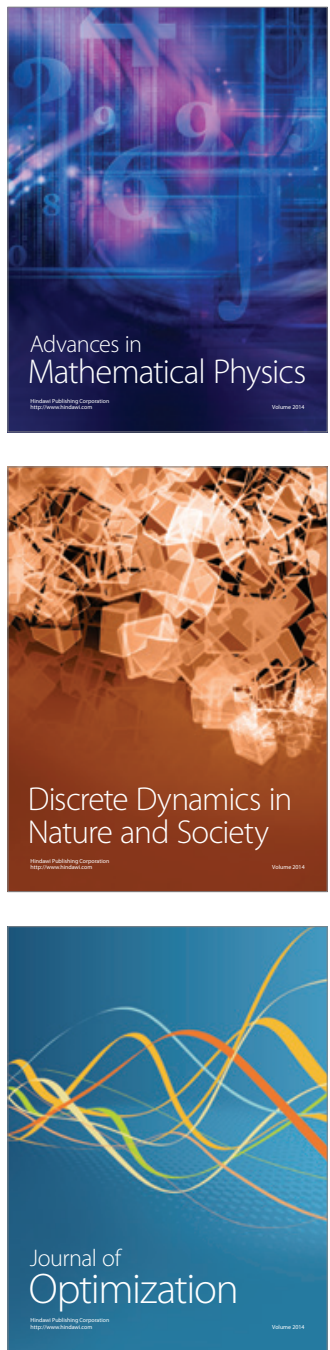